\title{
Management of precancerous conditions and lesions in the stomach (MAPS): guideline from the European Society of Gastrointestinal Endoscopy (ESGE), European Helicobacter Study Group (EHSG), European Society of Pathology (ESP), and the Sociedade Portuguesa de Endoscopia Digestiva (SPED)
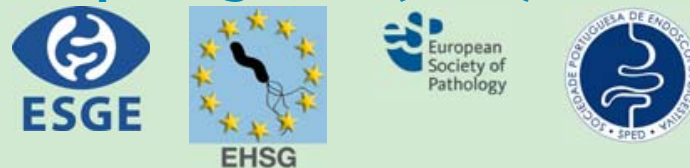

Authors

M. Dinis-Ribeiro" ${ }^{\circ 1,5}$, M. Areia ${ }^{2,5}$, A. C. de Vries ${ }^{3}$, R. Marcos-Pinto ${ }^{4,6}$, M. Monteiro-Soares ${ }^{5}$, A. O'Connor ${ }^{7}$, C. Pereira ${ }^{8}$, P. Pimentel-Nunes ${ }^{1}$, R. Correia ${ }^{5}$, A. Ensari ${ }^{\dagger, 9}$, J. M. Dumonceau ${ }^{\ddagger}, 10$, J. C. Machado ${ }^{11}$, G. Macedo ${ }^{\S, 12}$, P. Malfertheiner ${ }^{13}$, T. Matysiak-Budnik ${ }^{14}$, F. Megraud ${ }^{15}$, K. Miki ${ }^{16}$, C. O'Morain ${ }^{7}$, R. M. Peek ${ }^{17}$, T. Ponchon ${ }^{18}$, A. Ristimaki ${ }^{19,20}$, B. Rembacken ${ }^{21}$, F. Carneiro ${ }^{\Uparrow, 11,22}$, E. J. Kuipers ${ }^{3}$ on behalf of MAPS Participants ${ }^{* *}$ (see below and Appendix)

Institutions

Institutions are listed at the end of article.

Submitted: 4. August 2011 Accepted after revision: 12. October 2011

\section{Bibliography}

Dol http://dx.doi.org/

10.1055/s-0031-1291491

Endoscopy 2012; 44: 74-94

(c) Georg Thieme Verlag KG

Stuttgart · New York

ISSN 0013-726X

\section{Corresponding author} M. Dinis-Ribeiro, MD PhD

Gastroenterology Department Portuguese Oncology Institute of Porto

Rua Dr. Bernardino de Almeida 4200-072 Porto

Portugal

Fax: +351-22-5084055

mdinisribeiro@gmail.com
Atrophic gastritis, intestinal metaplasia, and epithelial dysplasia of the stomach are common and are associated with an increased risk for gastric cancer. In the absence of guidelines, there is wide disparity in the management of patients with these premalignant conditions. The European Society of Gastrointestinal Endoscopy (ESGE), the European Helicobacter Study Group (EHSG), the European Society of Pathology (ESP) and the Sociedade Portuguesa de Endoscopia Digestiva (SPED) have therefore combined efforts to develop evidence-based guidelines on the management of

\section{INTRODUCTION}

Gastric cancer remains a major problem worldwide. The intestinal type of gastric cancer develops through a cascade of well-defined and recognizable precursors (inflammation-metaplasiadysplasia-carcinoma sequence) [1]. It has been argued that the identification and surveillance of patients with such precursor conditions and lesions may lead to early diagnosis of gastric cancer. Indeed, this may be an important measure for prevention of death due to gastric cancer both in Western and Asian countries. However, even

\footnotetext{
* Chairman, ESGE Educational Committee, and Chairman, SPED Research Committee

${ }^{\dagger}$ Chairperson, ESP Digestive Pathology Working Group

$\ddagger$ Chairman, ESGE Guidelines Committee

$\S$ President, Portuguese Society of Digestive Endoscopy

${ }^{9}$ ESP Digestive Pathology Working Group

** Including: Cathomas G (Switzerland), Fedorov ED (Russia), Figueiredo P (Portugal), Goldis A (Romania), Leja M (Latvia), Moehler M (Germany), Plesea E (Romania), Bergman J (The Netherlands), Hamoudi W (Jordan), Almeida R, Annibale B, Lobo LA, Balaban YH, Boeriu A, Burette A, Mallet AC, David L, Delchier J-C, Dobru ED, Fernandes C, Kahaleh M, Kashin S, Lomba-Viana R, Lunet N, Marakhouski K, Moreira-Dias L, Ferreira CF, Pais TP, Rollán A, Sadio A, Santos C, Chu K-M, D'Ambra G, Ellul P, van Grieken N, Lamarque D, Najeeb AA
}

patients with precancerous conditions and lesions of the stomach (termed MAPS). A multidisciplinary group of 63 experts from 24 countries developed these recommendations by means of repeat online voting and a meeting in June 2011 in Porto, Portugal. The recommendations emphasize the increased cancer risk in patients with gastric atrophy and metaplasia, and the need for adequate staging in the case of high grade dysplasia, and they focus on treatment and surveillance indications and methods.

though such lesions are commonly found in everyday practice, there are no international recommendations to guide clinicians in their care of individuals with these changes. This leads to wide heterogeneity of practice and to failure to diagnose patients with curable forms of cancer. Standardization of management is likely to benefit patients, and may also be cost-effective by focusing resources on patients with the greatest risk.

This consensus project aimed to summarize current evidence on the management of patients with precancerous conditions and lesions, and to propose guidelines for the diagnosis and management of individuals with chronic gastritis, atrophy, intestinal metaplasia, or dysplasia.

This Guideline does not address methodologies for screening these lesions in general populations, or the assessment and management of patients with other precancerous conditions, such as pernicious anemia, Ménétrier disease, or gastric stump, or treatment for gastric adenocarcinoma.

\section{Scope and key questions}

We addressed the management, that is, the diagnostic assessment, treatment and follow-up, of individuals with atrophic gastritis, or intestinal metaplasia or dysplasia of the gastric mucosa. Specific issues were included: What is the optimal diagnostic approach for patients with gastric 
Table 1 Panel subgroups according to key questions.

\begin{tabular}{|c|c|}
\hline Key questions & Working group \\
\hline $\begin{array}{l}\text { Which are the precancerous lesions in the stomach? } \\
\text { Which outcomes to prevent/avoid? }\end{array}$ & Fátima Carneiro, Ernst Kuipers, Mário Dinis Ribeiro \\
\hline $\begin{array}{l}\text { Is there evidence to use endoscopic methods to improve } \\
\text { diagnosis? }\end{array}$ & $\begin{array}{l}\text { Miguel Areia, Pedro Pimentel Nunes, AnneMarie de Vries, Bjorn Rembacken, Ernst Kuipers, Mário } \\
\text { Dinis Ribeiro, }\end{array}$ \\
\hline $\begin{array}{l}\text { Which care should be taken on biopsies (number and } \\
\text { sites) for a correct diagnosis and staging? }\end{array}$ & $\begin{array}{l}\text { Ricardo Marcos Pinto, Bjorn Rembacken, Kazumasa Miki, José Carlos Machado, Fátima Carneiro, } \\
\text { Ernst Kuipers, Mário Dinis Ribeiro, }\end{array}$ \\
\hline Should other sources of data be added for staging? & $\begin{array}{l}\text { Ricardo Marcos Pinto, Carina Pereira, José Carlos Machado, Miguel Areia, AnneMarie de Vries, } \\
\text { Fátima Carneiro, Ernst Kuipers, Mário Dinis Ribeiro, Thierry Ponchon, Bjorn Rembacken, Kazu- } \\
\text { masa Miki }\end{array}$ \\
\hline $\begin{array}{l}\text { Is there evidence to use non-invasive methods to } \\
\text { improve diagnosis? }\end{array}$ & Miguel Areia, Ernst Kuipers, Mário Dinis Ribeiro, Kazumasa Miki, \\
\hline Should these patients be followed up? & AnneMarie de Vries, Ernst Kuipers, Mário Dinis Ribeiro, Ricardo Marcos Pinto, Carina Pereira \\
\hline $\begin{array}{l}\text { Does the type, the severity and the extension of the } \\
\text { lesion influence the prognosis of these patients? }\end{array}$ & $\begin{array}{l}\text { AnneMarie de Vries, Ernst Kuipers, Mário Dinis Ribeiro, Thierry Ponchon, Bjorn Rembacken, } \\
\text { Kazumasa Miki, José Carlos Machado, Ricardo Marcos Pinto, Carina Pereira, Fátima Carneiro }\end{array}$ \\
\hline Is there a role for Helicobacter pylori eradication? & $\begin{array}{l}\text { Anthony O’Connor, Pedro Pimentel-Nunes, Ernst Kuipers, Mário Dinis Ribeiro, Peter } \\
\text { Malfertheiner, Tamara Matysiak-Budnik, Francis Megraud, Carina Pereira, Ari Ristimaki }\end{array}$ \\
\hline Is there a role for other therapies? & $\begin{array}{l}\text { Anthony O'Connor, Carina Pereira, Ernst Kuipers, Mário Dinis Ribeiro, Peter Malfertheiner, } \\
\text { Tamara Matysiak-Budnik, Francis Megraud, Pedro Pimentel-Nunes }\end{array}$ \\
\hline May it/these strategies be cost-effective? & Miguel Areia, Richard Peek, Jean-Marc Dumonceau, Ernst Kuipers, Mário Dinis Ribeiro \\
\hline
\end{tabular}

precancerous conditions/lesions? Which patients are at higher risk and would benefit from surveillance to detect early-stage cancer? Should they receive pharmacological interventions to reduce the risk of developing cancer? If so, are such measures costeffective?

\section{METHODS}

$\nabla$

These recommendations were developed according to the process described by the Appraisal of Guidelines for Research and Evaluation (AGREE) Collaboration [2].

\subsection{Selection of Working Panel}

In May 2010, three authors (M.D.R., E.J.K., and F.C.), on behalf of the European Society of Gastrointestinal Endoscopy (ESGE), the Sociedade Portuguesa de Endoscopia Digestiva (SPED), the European Helicobacter Study Group (EHSG), and the European Society of Pathology (ESP), assembled a panel of European gastroenterologists and pathologists, including clinical experts and young researchers trained in literature search and evidence-based medicine (see Appendix).

This panel met in October 2010 in Barcelona, and agreed on the methodology to be applied, and on a set of key questions and preliminary statements to guide a literature search. The panel further worked in subgroups ( $\bullet$ Table 1 ) to perform a systematic search for evidence, to review statements on the basis of quality-rated evidence, and to report graded statements and recommendations accordingly. Subsequently representatives from European national societies of digestive endoscopy and pathology, and individual members (see Appendix), considered the applicability of the evidence and draft statements. This was done by means of two online sessions for voting and comments, followed by a second meeting held in June 2011 in Porto, Portugal.

A total of 63 participants contributed (all online and 45 in Porto), including participants from Belarus, Belgium, Brazil, China, Chile, Finland, France, Germany, Iraq, Ireland, Italy, Jordan, Latvia, Malta, Portugal, Romania, Russia, Slovakia, Sudan, Switzerland, The Netherlands, Turkey, UK and USA. In addition, nine national so- cieties were represented (Germany, Jordan, Latvia, Portugal, Romania, Russia, Slovakia, Switzerland and The Netherlands).

\subsection{Literature search}

A literature search using PubMed up to November 2010 was carried out. A small working group from the panel dealt with each question and each string/query, and identified key references which were supplied to the entire panel and participants.

\subsection{Grading of evidence}

Each working group rated the quality level of the available evidence and the strength of recommendations by using both the Grading of Recommendations, Assessment, Development, and Evaluation (GRADE) process [3, 4] and the system of the Scottish Intercollegiate Guidelines Network (SIGN) [5]. Researchers prioritized data from randomized clinical trials (RCTs) when available, and performed meta-analyses when applicable. Each paper was individually assessed by two investigators using a methodological tool that was identical for all topics reviewed in the guidelines. Discrepant assessment results were discussed by the full working group. Tables with the assessment of individual manuscripts are available upon request.

For each question the working group summarized the quantity, quality, and consistency of evidence, and they discussed the external validity of studies and whether the study conclusions were applicable to the target population for the guidelines. The group recorded the overall level of evidence addressing the key question and made a graded recommendation pertaining to the key question (for evidence levels and recommendation grades, see - Table 2 ).

It is important to emphasize that the grading does not relate to the importance of the recommendation, but to the strength of the supporting evidence.

Other factors that influenced the grading of a recommendation were taken into account by the participants, including: (i) any evidence of potential harms associated with implementation of a recommendation; (ii) clinical impact on the target population and impact on resource consumption; (iii) whether, and to what extent, any patient populations might be particularly advantaged 


\begin{tabular}{|c|c|}
\hline \multicolumn{2}{|c|}{ Levels } \\
\hline $1++$ & High quality meta-analyses, systematic reviews of RCTs, or RCTs with a very low risk of bias \\
\hline $1+$ & Well conducted meta-analyses, systematic reviews of RCTs, or RCTs with a low risk of bias \\
\hline $1-$ & Meta-analyses, systematic reviews or RCTs, or RCTs with a high risk of bias \\
\hline $2++$ & $\begin{array}{l}\text { High quality systematic reviews of case - control or cohort studies } \\
\text { OR High quality case - control or cohort studies with a very low risk of confounding, bias, or chance and a } \\
\text { high probability that the relationship is causal }\end{array}$ \\
\hline $2+$ & $\begin{array}{l}\text { Well conducted case - control or cohort studies with a low risk of confounding, bias, or chance and a } \\
\text { moderate probability that the relationship is causal }\end{array}$ \\
\hline $2-$ & $\begin{array}{l}\text { Case - control or cohort studies with a high risk of confounding, bias, or chance and a significant risk that the } \\
\text { relationship is not causal }\end{array}$ \\
\hline 3 & Non-analytic studies, e. g. case reports, case series \\
\hline 4 & Expert opinion \\
\hline \multicolumn{2}{|c|}{ Grades } \\
\hline A & $\begin{array}{l}\text { At least one meta-analysis, systematic review, or RCT rated as } 1++ \text {, and directly applicable to the target } \\
\text { population; } \\
\text { OR a systematic review of RCTs } \\
\text { OR A body of evidence consisting principally of studies rated as } 1+\text {, directly applicable to the target } \\
\text { population, and demonstrating overall consistency of results }\end{array}$ \\
\hline B & $\begin{array}{l}\text { A body of evidence including studies rated as } 2++ \text {, directly applicable to the target population, and } \\
\text { demonstrating overall consistency of results; } \\
\text { OR Extrapolated evidence from studies rated as } 1++ \text { or } 1+\end{array}$ \\
\hline C & $\begin{array}{l}\text { A body of evidence including studies rated as } 2+\text {, directly applicable to the target population and } \\
\text { demonstrating overall consistency of results; } \\
\text { OR Extrapolated evidence from studies rated as } 2++\end{array}$ \\
\hline D & $\begin{array}{l}\text { Evidence level } 3 \text { or } 4 \\
\text { OR Extrapolated evidence from studies rated as } 2+\end{array}$ \\
\hline
\end{tabular}

Table 2 Scottish Intercollegiate Guidelines Network (SIGN) system: definitions of levels of evidence and recommendation grades.

$\mathrm{RCT}$, randomized controlled trial

or disadvantaged by the recommendations; and (iv) opportunities and obstacles regarding implementation in daily clinical practice.

\subsection{Consensus process and applicability}

A hybrid approach was used to obtain the final version of statements, starting with an online consultation followed by a final meeting in Porto, in June 2011. Online questionnaires (MedQuest) were devised to allow participants to vote anonymously on statements. During the first round the panel members were asked to vote on their agreement with evidence-based statements; and in a second round, all participants, that is, panelists, society representatives, and individual members, were asked to vote on their agreement with statements but also on the level of applicability. At this stage, a collection of summarized references were available to all participants. The final discussion took place in June 2011 in Porto, during a one-day consensus conference, where data were presented and discussed; this was followed by re-voting and attribution of grades to the final statements.

(Voting was on a 6-point scale: a, agree strongly; b agree moderately; c, just agree; d, just disagree; e, disagree moderately; and f, disagree strongly. Prior to the voting process it was defined that a statement would be accepted if more than $75 \%$ of the participants voted $\mathrm{a}, \mathrm{b}$, or $\mathrm{c}$.

In addition, in the second round, all participants were also specifically queried regarding the level of applicability to their own practice and in their country, when this was relevant.

\subsection{Reporting}

The present manuscript summarizes the results of this entire process and was reviewed by all participants. Moreover, all ESGE individual members and national societies were asked to send their contributions.

Agreement results are presented as proportions of voters agreeing with the statements. The online voting results are presented for the statements that remained unchanged during the Porto meeting. For those for which a new voting process was conducted during the meeting in Porto, the final results for that meeting are presented. We also present a flow chart of the final results.

\section{RESULTS}

\section{$\nabla$}

\subsection{Summary of recommendations}

Conventional white light endoscopy cannot accurately differentiate between and diagnose pre-neoplastic gastric conditions/lesions (evidence level $2++$, recommendation grade $\mathrm{B}$ ). Thus, magnification chromoendoscopy or narrow-band imaging (NBI) endoscopy with or without magnification may be offered in these cases as it improves diagnosis of such lesions (evidence level $2+$ + , recommendation grade $B$ ). In addition, at least four biopsies of the proximal and distal stomach, on the lesser and greater curvature, are needed for adequate assessment of premalignant gastric conditions (evidence level $2+$, recommendation grade C). Systems for histopathological staging (e.g. operative link for gastritis assessment [OLGA] and operative link for gastric intestinal metaplasia [OLGIM] assessment) may be useful for identifying subgroups of patients with different risks of progression to gastric cancer (evidence level $2++$, recommendation grade $\mathrm{C}$ ), namely those with extensive lesions (i.e., atrophy and/or intestinal metaplasia in both antrum and corpus). Although only low potential applicability was reported by participants for this indicator, low serum pepsinogen levels can also predict this phenotype (evidence level $2++$, recommendation grade $\mathrm{C}$ ) and, in such patients, Helicobacter pylori serology may also be useful for further detection of high risk individuals (evidence level $2++$, recommendation grade $\mathrm{C}$ ). Beyond a family history of gastric cancer (evidence level $2++$, recommendation grade $B$ ), neither age, gender, $\mathrm{H}$. pylori virulence factors, or host genetic variations change these clin- 


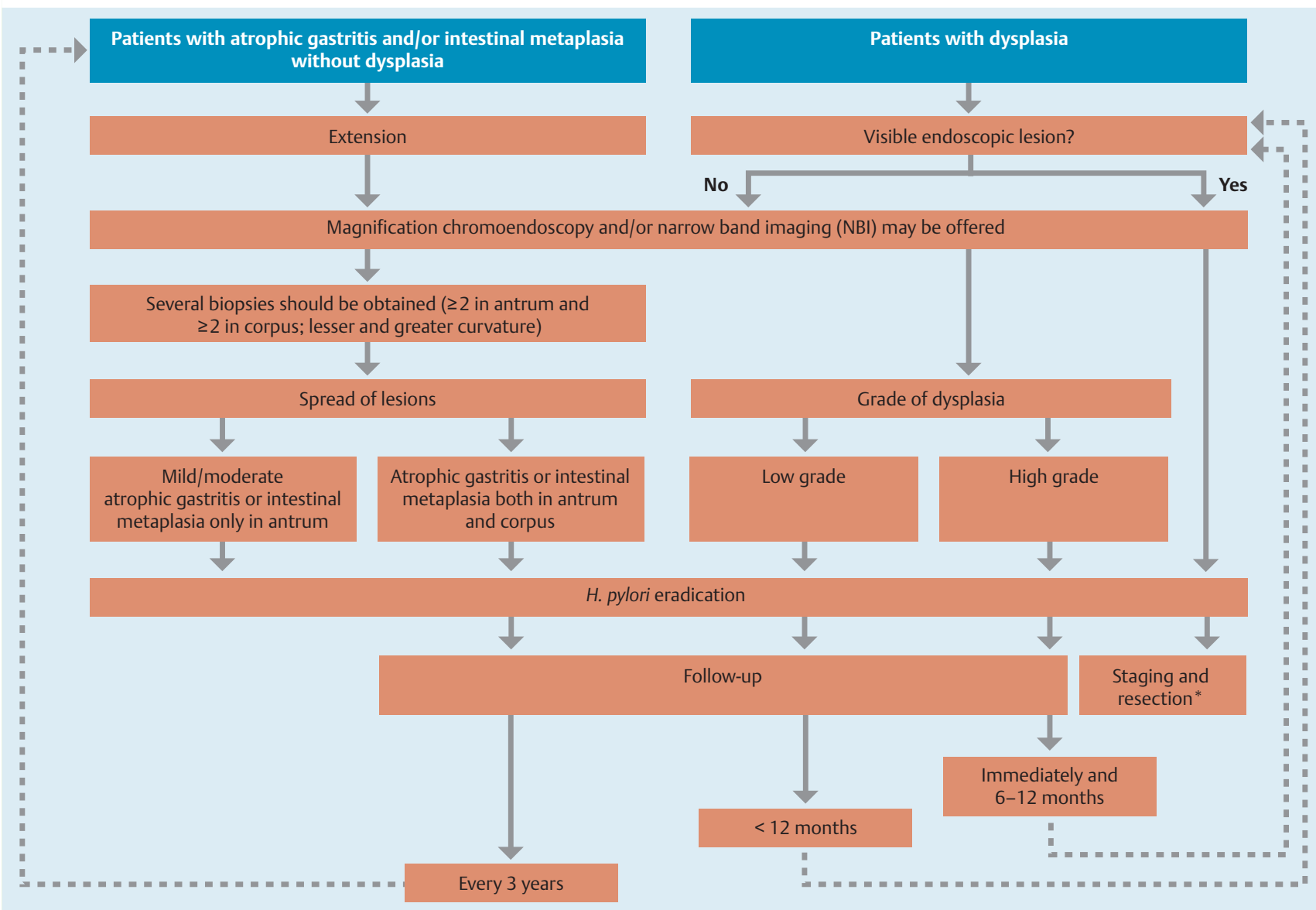

Fig. 1 Summary of proposed management for patients with atrophic gastritis, gastric intestinal metaplasia and gastric epithelial dysplasia. ${ }^{*}$ The further management is not covered by this guideline.

ical recommendations (evidence level 4, recommendation grade D). Patients with extensive atrophy and/or extensive intestinal metaplasia should be offered endoscopic surveillance (evidence level $2++$, recommendation grade B) every 3 years (evidence level 4 , recommendation grade D). Further studies are needed however, to accurately estimate the cost- effectiveness of such an approach (evidence level 1, recommendation grade B). Patients with mild to moderate atrophy/intestinal metaplasia only in antrum do not need follow-up (evidence level 4, recommendation grade D). If $H$. pylori infection is present, eradication should be offered to prevent high grade dysplasia or carcinoma (evidence level $1+$, recommendation grade $B$ ). Currently, the use of cyclooxygenase-2 (COX-2) inhibitors or the use of dietary supplementation with antioxidants (ascorbic acid and beta-carotene) are not endorsed as approaches to decrease the risk of progression of gastric precancerous lesions (evidence level $1+$, recommendation grade B). Patients with dysplasia without a visible endoscopic lesion should be closely followed up, either immediately and 6 to 12 months thereafter, or within 12 months ( evidence level $2+$, recommendation grade $C$ ), respectively, for those with high grade or low grade dysplasia. Those with dysplasia or cancer within an endoscopically visible lesion should undergo staging and resection.

A flow chart for the proposed management of patients with atrophic gastritis, gastric intestinal metaplasia, or gastric epithelial dysplasia is shown in $\bullet$ Fig. 1.

\subsection{Definitions and outcomes to prevent}

\subsubsection{Gastric carcinogenesis}

1. Patients with chronic atrophic gastritis or intestinal metaplasia should be considered to be at higher risk for gastric adenocarcinoma. (Agree 96\% [vote: a, 68\%; b, 18\%; c, 10\%; d, 2\%; e, 2\%])

2. High grade dysplasia and invasive carcinoma should be regarded as the outcomes to be prevented when patients with chronic atrophic gastritis or intestinal metaplasia are managed. (Agree $96 \%$ [vote: a, $72 \%$; b, 14\%; c, 10\%; d, 4\%])

3. Patients with endoscopically visible high grade dysplasia or carcinoma should undergo staging and adequate management. (Agree 100\% [vote: a, 94\%; b, 2\%; c, 4\%])

In most instances, the development of so-called "intestinal" gastric adenocarcinoma represents the culmination of an inflammation-metaplasia - dysplasia-carcinoma sequence, known as the Correa cascade of multistep gastric carcinogenesis, where a progression may occur from normal mucosa through chronic nonatrophic gastritis ( $\bullet$ Fig.2a,b), atrophic gastritis ( Fig.2c,d), and intestinal metaplasia ( $\mathbf{F i g . 2 e , f}$ ), to dysplasia ( $\bullet \mathbf{F i g . 2} \mathbf{g}$ ) and carcinoma [6-8]. This model has been consistently confirmed in different studies $[9,10]$.

\subsubsection{Precancerous conditions}

Mucosal gastric atrophy and intestinal metaplasia confer a high risk for the development of gastric cancer as they constitute the background in which dysplasia and intestinal-type gastric adenocarcinoma develop [7, 11-13]. Thus, chronic atrophic gastritis 

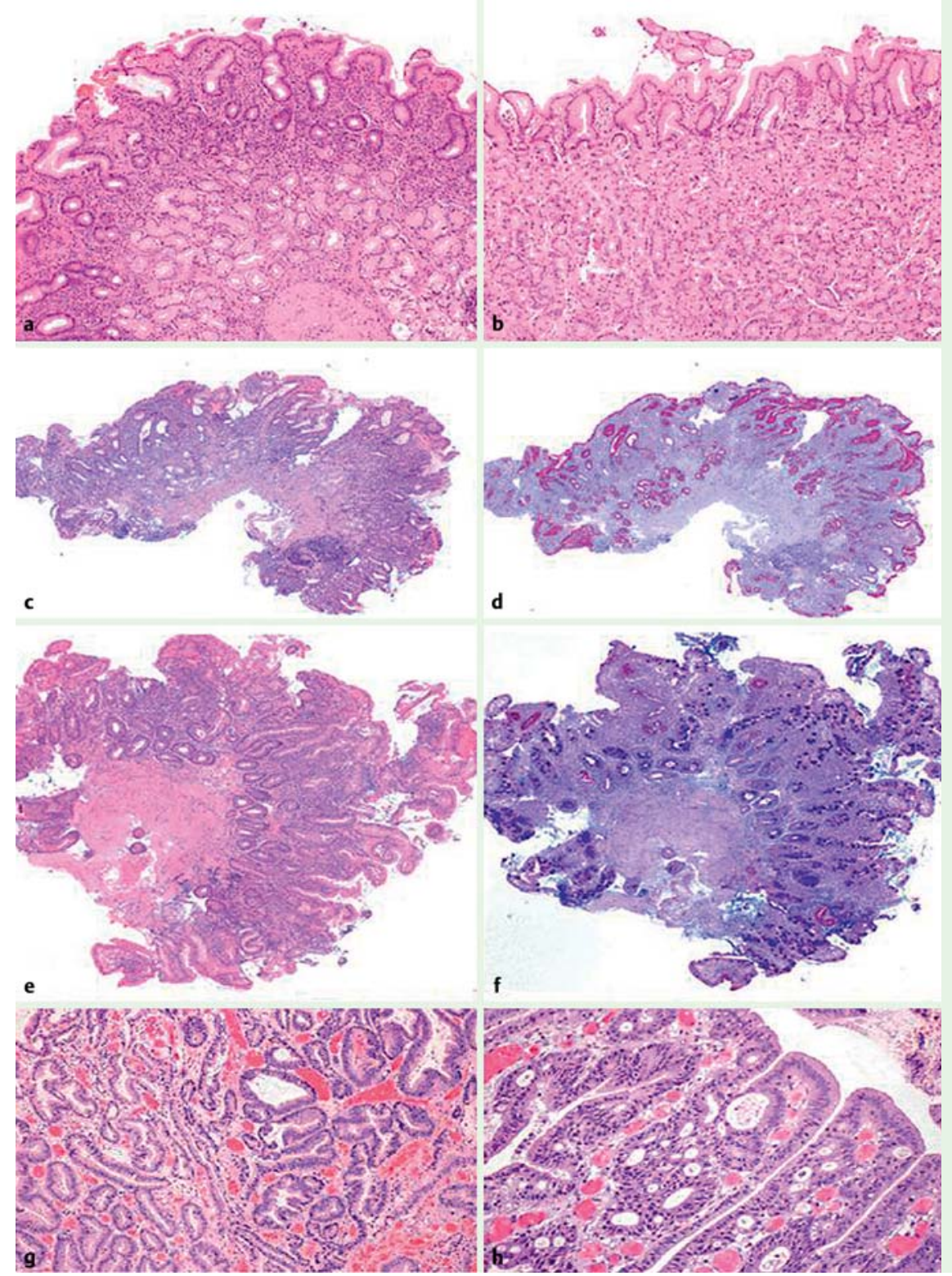

Fig. 2 Morphologic changes in gastric mucosa during gastric carcinogenesis. a,b Non-atrophic gastritis, without gland atrophy and/or intestinal metaplasia: (a) antrum (hematoxylin and eosin [H\&E], × 40); (b) corpus (H\&E, × 100). c,d Moderate atrophy of deep antral glands (gland loss between $30 \%$ and $60 \%$ ), without intestinal metaplasia: (c) H\&E staining, $\times 40$; (d) Periodic acid - Schiff (PAS) alcian blue staining, $\times 40$, highlighting gland loss and a single focus of intestinal metaplasia in the superficial part of the gastric mucosa. e,f Severe atrophy of antral mucosa, with loss of more than $60 \%$ of original mucous-secreting glands, replaced by intestinal metaplasia: (e) H\&E, × 40; (f) PASalcian blue, $\times 40$. g,h Dysplasia and intramucosal carcinoma: (g) low grade (left) and high grade (right) dysplasia (H\&E, × 100); (h) intramucosal carcinoma $(H \& E, \times 200)$. and intestinal metaplasia are considered to be precancerous conditions.

Chronic atrophic gastritis should be diagnosed and graded on the basis of the presence of chronic inflammatory cells, including lymphocytes and plasma cells that expand the lamina propria, and the disappearance of the normal glands [14-16]. In the gastric body/fundus this is associated with a loss of specialized cells and thus a reduction of gastric secretory functions. The severity of gland loss (atrophy) should be graded although inter- and intraobserver agreement are both poor.

Individuals may develop different phenotypes of chronic gastritis due to different genetic profiles and environmental exposure:

- Cases of inflammatory changes limited to the antrum and without gland atrophy and/or intestinal metaplasia are defined as diffuse antral gastritis.

- Cases of gland atrophy and/or intestinal metaplasia distributed multifocally including the lesser curvature of the corpus and fundus, are defined as multifocal atrophic gastritis. This phenotype may be described as "extensive," whereas the term "marked" is used to define a severity grade at a particular site.
The overall background changes in the stomach should therefore be described in terms of the severity and distribution of any premalignant conditions/lesions. Several classification schemes have been developed for chronic gastritis and preneoplastic changes. At present, the updated Sydney System is generally used both in clinical practice and in research, combining topographic, morphological, and etiological information in reporting systems designed to include both grading and staging of gastritis. In addition, the systems known as OLGA (operative link for gastritis assessment), and OLGIM (operative link on gastric intestinal metaplasia) assessment have been proposed for staging of gastritis (see below). However, most classifications are still difficult to use in clinical practice, and when applied they have the disadvantage of considerable inter- and intraobserver variation.

Nevertheless, these systems seem to be more relevant and easy to apply than subtyping of intestinal metaplasia. Intestinal metaplasia may be classified as "complete" or "incomplete." Complete intestinal metaplasia ("small-intestinal" or type I) displays goblet and absorptive cells, decreased expression of gastric mucins (MUC1, MUC5AC, and MUC6), and expression of MUC2, an intes- 
tinal mucin. Incomplete intestinal metaplasia ("enterocolic" or type IIA/II, and "colonic" or type IIB/III), displays goblet and columnar non-absorptive cells [17-20], in which gastric mucins (MUC1, MUC5AC, and MUC6) are coexpressed with MUC2 [1720]. In Filipe's classification the typing of intestinal metaplasia (types I, II, and III) was based on the detection of sialomucin and sulphomucin by high iron diamine - alcian blue staining (this approach was discontinued due to toxicity of the reagents). Currently used classifications also take into consideration the presence of Paneth cells (complete metaplasia) or crescent architecture changes, dedifferentiation, and degree of absence of Paneth cells (incomplete metaplasia), as well as the pattern and type of mucin expression [20]. Moreover, some studies indicate a positive correlation between the degree of incomplete intestinal metaplasia and the extent of intestinal metaplasia. However, the use of immunohistochemistry or other special techniques in order to subtype intestinal metaplasia is not widespread in routine diagnostics.

Recently, another pattern of metaplasia, termed spasmolytic polypeptide-expressing metaplasia (SPEM), has been described. This is characterized by the expression of the TFF2 spasmolytic polypeptide that is associated with oxyntic atrophy. SPEM, which characteristically develops in the gastric body and fundus, appears to share some characteristics with pseudopyloric metaplasia, has a strong association with chronic infection with Helicobacter pylori and with gastric adenocarcinoma, and may represent another pathway to gastric neoplasia [21]. At present identification of SPEM is considered an investigational parameter.

\subsubsection{Precancerous lesions}

Gastric dysplasia represents the penultimate stage of the gastric carcinogenesis sequence, is defined as histologically unequivocal neoplastic epithelium without evidence of tissue invasion, and is thus a direct neoplastic precancerous lesion [22]. It is characterized by cellular atypia reflective of abnormal differentiation, and disorganized glandular architecture [23-26]. Correct diagnosis and grading of dysplasia are critical, because they predict both the risk of malignant transformation and the risk of metachronous gastric cancer. In fact, the reported progression rates of dysplasia to gastric cancer vary greatly, from $0 \%$ to $73 \%$ per year [27-48]. These variations can probably be explained by diverse factors such as differences in study design and populations under study and also differences in definitions and assessment of gastric dysplasia.

There are well-known differences between Japanese and European/North American pathologists in categorizing gastric dysplasia that in some classifications is designated as intraepithelial neoplasia. For instance, in Japan, noninvasive intramucosal neoplastic lesions with high grade cellular and architectural atypia are termed "non-invasive intramucosal carcinoma," whereas the same lesions are diagnosed as high grade dysplasia by most pathologists in the West $[49,50]$.

In an attempt to resolve this issue, several proposals have been made regarding the terminology for the morphological spectrum of lesions, including the Padova and Vienna classifications and more recently, the World Health Organization (WHO) classification.

The WHO recently reiterated the classification of dysplasia/intraepithelial neoplasia. Acknowledging the widespread use of both "dysplasia" and "intraepithelial neoplasia" (IEN), it uses these terms as synonymous (in this paper, dysplasia is the term that will be used from now on). According to the current WHO classification [51], the following diagnostic categories should thus be considered:

1. Negative for intraepithelial neoplasia/dysplasia

2. Indefinite for intraepithelial neoplasia/dysplasia

3. Low grade intraepithelial neoplasia/dysplasia

4. High grade intraepithelial neoplasia/dysplasia

5. Intramucosal invasive neoplasia/intramucosal carcinoma.

In the stomach, and as far as the present guidelines are concerned, category 1, negative for intraepithelial neoplasia/dysplasia, includes chronic atrophic gastritis and intestinal metaplasia. Where there is doubt as to whether a lesion is neoplastic or nonneoplastic (i.e. reactive or regenerative), particularly in small biopsies exhibiting inflammation, the diagnosis should be indefinite for intraepithelial neoplasia/dysplasia. In such cases, the dilemma is usually solved by cutting deeper levels, by obtaining additional biopsies, or after correcting for possible etiologies.

Intraepithelial neoplasia/dysplasia comprises unequivocally epithelial neoplastic proliferations characterized by variable cellular and architectural atypia, but without convincing evidence of invasion. Low grade intraepithelial neoplasia/dysplasia shows minimal architectural disarray and only mild-to-moderate cytological atypia. The nuclei are elongated, polarized, and basally located, and mitotic activity is mild-to-moderate ( $\bullet$ Fig.2 g, left). High grade intraepithelial neoplasia/dysplasia comprises neoplastic cells that are usually cuboidal, rather than columnar, with a high nucleus-to-cytoplasm ratio, prominent amphophilic nucleoli, more pronounced architectural disarray, and numerous mitoses, which can be atypical. Importantly, the nuclei frequently extend into the luminal aspect of the cell, and nuclear polarity is usually lost ( Fig. $\mathbf{2 g}$, right). Most patients harboring lesions classified as high grade dysplasia are at high risk for either synchronous invasive carcinoma or its rapid development [34] (see below). Intramucosal invasive neoplasia/intramucosal carcinoma defines carcinomas that invade the lamina propria and are distinguished from intraepithelial neoplasia/dysplasia not only by desmoplastic changes that can be minimal or absent, but also by distinct structural anomalies, such as marked glandular crowding, excessive branching, budding, and fused or cribriforming glands ( $\bullet$ Fig. $\mathbf{2 h}$ ). The diagnosis of intramucosal carcinoma indicates that there is an increased risk of lymphatic invasion and lymphnode metastasis. However, endoscopic techniques allow treatment without open surgery, particularly for lesions $\leq 2 \mathrm{~cm}$ in size and for those that are well differentiated with no lymphatic invasion. Guidelines for endoscopic treatment of gastric adenocarcinoma are beyond the scope of this manuscript.

\subsection{Diagnosis and staging}

\subsubsection{Endoscopy}

4. Conventional white light endoscopy cannot accurately differentiate and diagnose pre-neoplastic gastric conditions. (evidence level $2++$, recommendation grade B). (Agree $94 \%$ [vote: a, $46 \%$; b, $24 \%$; c, $24 \%$; d, $4 \%$; e, $2 \%$ ])

5. Magnification chromoendoscopy and narrow band imaging (NBI), with or without magnification, improve the diagnosis of gastric preneoplastic conditions/lesions (evidence level $2++$, recommendation grade $B$ ). (Agree $98 \%$ [vote: a, $47 \%$; b, $27 \%$; c, $24 \%$;, $2 \%] 83 \%$ of voters stated that they would apply this statement; $67 \%$ of those representing national societies mentioned that it would also be applicable (63\%) or widely applicable (4\%) in their countries.) 
6. Within this context, diagnostic upper gastrointestinal endoscopy should include gastric biopsies sampling (evidence level 4, recommendation grade $D$ ). (Agree $93 \%$ [vote: a, $66 \%$; b, $18 \%$; c, $9 \% ; d, 7 \%]$ )

Some studies have evaluated whether conventional white light (WL) endoscopy can reliably distinguish Helicobacter pylori gastritis and gastric preneoplastic lesions from normal mucosa. In a pioneer study Atkins \& Benedict concluded that correlation between endoscopy and histology was poor [52]. This was confirmed in a subsequent prospective study, where Bah et al. concluded that it is not possible to reliably diagnose $H$. pylori gastritis with endoscopy alone [53]. Antral nodularity appears to be the only endoscopic sign with a high positive predictive value (>90\%) for $H$. pylori infection; however, it is, except in children, only present in a minority of patients with $H$. pylori gastritis [53-56]. Absence of rugae and presence of visible vessels in the gastric mucosa predict severe atrophy but with a relatively low sensitivity [57]. Intestinal metaplasia may appear as thin, white mucosal deposits [58]; however, the value of this or other endoscopic signs for the diagnosis of intestinal metaplasia remains unestablished. Taken together, these studies show that conventional endoscopy cannot reliably diagnose $H$. pylori gastritis, atrophy, or intestinal metaplasia [52, 54-58].

There is inconsistent evidence that new high resolution endoscopes are more reliable. Some studies show low accuracy for the diagnosis of gastric mucosal inflammation, atrophy and metaplasia, particularly with patients aged below 50 years and in particular when they have mild atrophy or metaplasia [59], but others suggest a good accuracy [60]. In addition to low accuracy, endoscopy findings were associated with low reproducibility [61] and therefore current evidence suggests that conventional endoscopy cannot be relied upon to correctly identify patients with atrophy or intestinal metaplasia.

Studies have suggested that chromoendoscopy, particularly with magnification, helps to identify lesions of intestinal metaplasia and dysplasia. Dinis-Ribeiro et al. proposed a classification for the diagnosis of these lesions that was reproducible and highly accurate [62]. The accuracy and reproducibility of this chromoendoscopy classification with methylene blue was maintained when it was submitted to external validation [63]. Chromoendoscopy using other solutions, such as indigo carmine, acetic acid, or hematoxylin, was also associated with high accuracy for the diagnosis of these lesions, particularly for dysplasia [64], [65]. Tanaka et al. reported that that the use of acetic acid was superior to that of indigo carmine [65].

However, high resolution magnifying endoscopy without chromoendoscopy also appears superior to standard endoscopy, allowing great accuracy for the diagnosis of $H$. pylori gastritis, intestinal metaplasia, and dysplasia [66-67]. No comparative study of magnification with or without chromoendoscopy has been made for the diagnosis of these lesions, despite the suggestion of Tanaka et al. that enhanced magnification chromoendoscopy with acetic acid is superior to conventional magnification endoscopy and indigo carmine chromoendoscopy [65].

So, current evidence suggests that magnification chromoendoscopy (MCE) improves accuracy for the detection of preneoplastic gastric lesions. However, this technique lengthens the time of the endoscopic procedure and adds to the workload of gastroenterology departments. Besides, patient tolerance, even with sedation, may be compromised. Taking all these considerations together, routine performance of MCE cannot be recommended, and its use should be restricted to centers experienced in this technique.
The recent technology of narrow band imaging (NBI) has been found to have good sensitivity and specificity for the diagnosis of gastric lesions [68-77]. However, there is no agreement on which NBI patterns are associated with gastric precancerous lesions. The NBI classification systems varied between studies, there was no external validation, and reproducibility was seldom evaluated. Only two studies used NBI without magnification [76, 77]. The latter method, which could be applied in routine clinical practice in contrast to magnification-NBI which is not practicable in an everyday clinical setting, requires some level of expertise and a type of scope that is available in only a few centers. Nevertheless, this indicates that NBI may be useful for the identification of different gastric lesions. However, before this technology can be endorsed, a simple classification system will have to be agreed upon and independently validated in a large prospective multicenter study.

It follows that the best available endoscopic method should be offered to individual patients, but, within the context of optimal identification of patients with precancerous conditions, diagnostic upper gastrointestinal endoscopy should include sampling with gastric biopsies.

\subsubsection{Biopsy sampling}

7. Atrophic gastritis and intestinal metaplasia are often unevenly distributed throughout the stomach. For adequate staging and grading of gastric precancerous conditions, at least four nontargeted biopsies of two topographic sites (at the lesser and greater curvature, from both the antrum and the corpus) should be taken and clearly labelled in separate vials; additional target biopsies of lesions should be taken (evidence level $2+$, recommendation grade C). (Agree 100\% [vote: a, 61\%; b, 25\%; c, 14\%]; $90 \%$ of voters stated that they would apply this statement; $80 \%$ of those representing national societies mentioned that it would also be applicable [60\%] or widely applicable [20\%] in their countries.)

8. Systems for histopathological staging (e.g. operative link for gastritis assessment [OLGA] and operative link for gastric intestinal metaplasia [OLGIM] assessment) may be useful for categorization of risk of progression to gastric cancer (evidence level $2++$, recommendation grade $C$ ). (Agree 98\% [vote: a, 39\%; b, $41 \%$; c, $18 \%$; e, $2 \%$ ]; $90 \%$ of voters stated that they would apply this statement; $70 \%$ of those representing national societies mentioned that it would also be applicable in their countries.)

Biopsy specimens of the stomach are essential to the establishment and grading of preneoplastic gastric lesions. The updated Sydney System is the most widely accepted for classification and grading of gastritis [14]. The system was primarily designed to provide standardization for reporting of gastric biopsies. The updated version recommended five biopsies, two from the antrum ( $3 \mathrm{~cm}$ from the pylorus, greater and lesser curvatures), one from the incisura, and two from the corpus (one from the lesser curvature, $4 \mathrm{~cm}$ proximal to the incisura, and one from the middle of the greater curvature); these sites were arbitrarily chosen. Although this biopsy protocol generally correctly establishes $H$. pylori status and chronic gastritis, the number of biopsies is controversial with regard to adequate staging of premalignant gastric lesions, mainly because of the multifocal nature of these lesions [78-82]. This multifocal nature affects their detectability, in turn affecting decisions regarding the patient's therapy or future surveillance $[1,6]$. 
Five good quality studies [78-80, 39, 84], in different population settings, addressed the number of biopsies needed for a precise grading of gastritis and intestinal metaplasia. El-Zimaity \& Graham [80] concluded that the biopsy protocol recommended by the Sydney System underestimated the presence of intestinal metaplasia and could identify corpus atrophy only when it was extensive; these authors recommended a minimum of eight biopsies. On the other hand, Guarner et al. [79] concluded that the Sydney recommendations for biopsy sites and number were sensitive for identification of $H$. pylori infection and preneoplastic lesions (in geographic areas with a high prevalence of gastric cancer). The additional value of biopsies from the incisura angularis is unclear and remains insufficiently established. Although this location is considered to be an area of early onset of atrophic-metaplastic transformation $[85,86]$, other studies reported that additional incisura biopsies added little information to those obtained from antrum and corpus $[78,83]$. On the other hand, deVries et al. [84] in a multicenter study, in a low gastric cancer risk population, evaluated the yield from endoscopic surveillance of premalignant gastric lesions, by standardized biopsy protocols with 12 non-targeted and additional targeted biopsies, in $112 \mathrm{pa}-$ tients with a previous histologically confirmed diagnosis of intestinal metaplasia or dysplasia. The highest prevalence of premalignant lesions was found in the incisura (40\%), followed by the antrum (35\%) and lesser curvature of the corpus (33\%). The nontargeted lesser curvature biopsies had a higher yield compared with those from the greater curvature of the corpus. A biopsy protocol consisting of seven non-targeted biopsies ( 3 antrum, 1 incisura, 3 from corpus, with 1 from the greater and 2 from the lesser curvature) was able to diagnose intestinal metaplasia in $97 \%$ of cases and all cases of dysplasia or cancer. Moreover, despite the low number of cases of gastric dysplasia in this study, it was shown that non-targeted biopsies were important for diagnosing dysplasia or even cancer.

The variability of sampling methods and results obtained is related to the prevalence of premalignant lesions in the studied population. Fewer biopsies are needed for accurate diagnosis and staging in high risk populations where the extent of the lesions is higher $[83,87,88]$. Even when extensive biopsy protocols are used, the inevitable sampling errors may affect the identification of the premalignant lesions which are frequently patchy $[14,80$, 89,90 ] and can be missed on follow-up [91]. However, the greater the extent of the lesion, the more likely it is to be found with regular biopsy sampling.

Although the Sydney system and its updated version [14] have contributed to uniformity of reporting of gastric preneoplastic lesions, they are not intended to be gastric cancer risk prediction tools. The aim of the recently established OLGA staging system (operative link for gastritis assessment) is to translate the histopathological data into a standardized report, with information on the gastric condition (topography and extent of the atrophic changes) and subgrouping of patients by cancer risk [92, 93]. Initially, two cross-sectional validation studies concluded that OLGA provides relevant clinical information, with identification of a subpopulation of patients (OLGA stage III/IV) with gastric premalignant lesions with high risk for gastric cancer and thus potentially eligible for surveillance of these lesions [94, 95]. Recently Rugge et al. [96] described a cohort of patients with premalignant gastric conditions/lesions followed for 12 years. Only two patients with OLGA grade III/IV developed invasive neoplasias $(P=0.001$; relative risk $[R R]=18.56)$. Because the OLGA system is based on the severity and extent of atrophy, a condition with low interobserver agreement [14, 97], Capelle et al. [98] introduced a modified system based on intestinal metaplasia, OLGIM (operative link for gastric intestinal metaplasia), with which there is a high level of interobserver concordance [99]. The agreement between pathologists was moderate for atrophy $(k=0.6)$ and higher for intestinal metaplasia $(k=0.9)$. Application of the OLGIM assessment was associated with categorization of fewer patients into the high risk stages III and IV. This has at least in theory the additional advantage that use of the OLGIM system would select a smaller population for whom surveillance would need to be considered. More studies on feasibility and reproducibility in different epidemiological contexts are needed to validate these classification systems [94].

Amongst these data, we have two good quality studies [96, 98] suggesting that for the identification of patients with severe atrophic changes, namely extensive atrophy and/or intestinal metaplasia, which identify patients at risk for dysplasia and/or cancer, biopsies should be taken in the corpus. In addition, other good quality case-control studies provided different conclusions, suggesting a minimum of 4 and a maximum of 8 biopsies for adequate staging and/or surveillance [78-80, 83, 84].

On this basis, the panel concluded that one should sample at least 2 biopsies from the antrum (greater and lesser curvature) and 2 biopsies from the corpus (greater and lesser curvature) to identify patients with atrophy and/or intestinal metaplasia. Biopsy samples should be submitted for pathological examination in different vials labelled according to the site of the sampling [14], [94].

\subsubsection{Noninvasive assessment}

9. Serum pepsinogen levels can predict extensive atrophic gastritis (evidence level $2++$, recommendation grade C). (Agree $92 \%$ [vote: a, $30 \%$; b, $28 \%$; c, 34\%; d, 4\%; e, $4 \%$ ]; $68 \%$ of voters stated that they would apply this statement; only $50 \%$ of those representing national societies mentioned that it would be applicable in their countries.)

10. In patients with low pepsinogen test levels, Helicobacter pylori serology may be useful for further detection of high risk individuals (evidence level $2++$, recommendation grade $C$ ). (Agree $76 \%$ [vote: a, $26 \%$; b, $10 \%$; c, $40 \%$; d, $18 \%$; e, $4 \%$; f, $2 \%$ ]; $77 \%$ of voters stated that they would apply this statement; $80 \%$ of those representing national societies mentioned that it would also be applicable [70\%] or widely applicable [10\%] in their countries.)

Serum pepsinogens (PGs) are related to atrophic changes in gastric mucosa and consist of two types: PGI, which is mainly secreted by the fundic mucosa, and PGII secreted by chief cells but also by the pyloric glands and the proximal duodenal mucosa. Inflammation of the gastric mucosa leads to an increase in both PGI and PGII serum levels, usually with a more marked increase of PGII and thus a decrease in the PGI/II ratio. With the development of atrophy and loss of specialized cells, both PGI and PGII may decrease, but PGI usually shows a more marked decrease than PGII, thus there is a further decline in the PGI/II ratio (see review by Kuipers EJ: "In through the out door: serology for atrophic gastritis," Eur J Gastroenterol Hepatol 2003: 877-879). Thus, a low PGI level, a low PGI/II ratio, or both, are good indicators of atrophic changes in the gastric mucosa.

Many studies have been conducted that compare the levels of the serum pepsinogens with the features of the gastric mucosa as characterized by endoscopy with biopsies, in different countries and populations and using several different cutoff values. The re- 
porting of results in terms of sensitivities and specificities but also as differences in serum pepsinogen mean levels, as correlations, or as odds ratios, makes it difficult to compare or generalize studies.

In a meta-analysis published in 2004, Dinis-Ribeiro et al. [100] combined 42 studies that included 27 population studies (296553 patients) and 15 selected-population studies (4385 patients), and looked for the best cutoff for dysplasia diagnosis. A combination of $\mathrm{PGI}<50 \mathrm{ng} / \mathrm{mL}$ and a PGI/PGII ratio 3.0 provided the best results, with a sensitivity of $65 \%$, a specificity of $74 \%-85 \%$ and a negative predictive value $>95 \%$. Most of the studies comparing serum pepsinogen levels with the histological assessment of the gastric mucosa were cross-sectional studies, from screening populations to selected high risk patients. Usually in these studies the gastroenterologist and the pathologist were blinded to each other's findings and both tests were done simultaneously.

When the study outcome was the extent of atrophy of the gastric corpus, values ranged between sensitivities of $9.4 \%$ to $92.3 \%$ and specificities of $9.9 \%$ to $100 \%$ [ $101-119]$, but other methods of reporting results found statistically significantly lower mean values of serum pepsinogen in extensive atrophic gastritis [105, 110, 120-123], significant correlations between atrophy extent and serum pepsinogen values [101, 124, 125], or significant odds/ likelihood ratios for progression of atrophy to the corpus [112, $126,127]$.

When the study outcome was the presence or extent of intestinal metaplasia, results presented sensitivity values of $15 \%-75 \%$ and specificity values of $92.2 \%-97.8 \%[102,115,128]$, or significant odds ratios [126, 127, 129].

When the study outcome was dysplasia/gastric cancer, some well-designed cohort studies were found reporting large numbers of patients followed-up for many years, together with several other case series reports or case - control studies.

The best evidence on the risk associated with premalignant gastric lesions comes from well-designed cohort studies, preferably with long follow-up times, including a large number of patients, and with small numbers lost to follow-up. At least six cohort studies fulfilling these criteria have been published to date. Watabe et al. [130] conducted a cohort study of 6983 patients for 4.7 years and found that $H$. pylori-positive patients with a PGI $<70 \mathrm{ng} / \mathrm{mL}$ and a PGI/II ratio $<3.0$ had a hazard ratio (HR) for gastric cancer of 6.0 (95\% confidence intervals [95\%CI] $2.4-$ 14.5); in $H$. pylori-negative patients with the same pepsinogen profile the HR increased to 8.2 (3.2-21.5). Yamaji et al. [131], in a study with 6158 patients followed for 4.7 years, found an HR of 6.2 (2.9-13.0), whilst Yanaoka et al. [132, 133], in 5209 patients followed for 10 years, obtained a HR of 2.77 (1.465.26). Ohata et al. [134] studied a cohort of 4655 patients for 7.7 years after collecting serum for pepsinogen and $H$. pylori antibodies; they concluded that in patients who were $H$. pylori-positive, with chronic atrophic gastritis by pepsinogen definition, the HR was 14.85 (1.96-107.7), whilst for patients who were $H$. pylori-negative with severe chronic atrophic gastritis the HR increased to 61.85 (5.6-682.64). Oishi et al. [135] followed 2466 patients for 12 years and found that a PGI level $<70 \mathrm{ng} / \mathrm{mL}$ with a PGI/II ratio <3.0 was linked with an HR for gastric cancer of $3.42(1.92-6.11)$, and a PGI $<30 \mathrm{ng} / \mathrm{mL}$ with a PGI/II ratio $<2.0$ related to an HR of 4.43 (2.18-7.82). Finally, Dinis-Ribeiro et al., in a cohort of 100 patients followed for 3 years, found that the combination of incomplete intestinal metaplasia and a PGI/ PGII ratio <3 was significantly associated with progression to dysplasia, with an HR of 13.9 (1.6-122.1) when compared with patients with only chronic atrophic gastritis or complete intestinal metaplasia [136].

Some of these studies also evaluated the presence of $H$. pylori and found that the most advanced and severe cases of gastric atrophy judged by the pepsinogen assessment, when combined with a negative $H$. pylori serology, probably due to a spontaneous disappearance of $H$. pylori antibody, were associated with an even greater progression to dysplasia and cancer. The values of hazard ratios of severely atrophic $H$. pylori-negative cases versus less atrophic $H$. pylori-positive cases were: $8.2(3.2-21.5)$ vs. 6.0 in the study of Watabe et al. [130], 131.98 (11.95-1457.36) vs. 2.77 in that of Yanaoka et al. [132,133], and 61.85 (5.6-682.64) vs. 14.85 in that of Ohata et al. [134]. Yamaji et al. also found an increased incidence of gastric cancer, from $0.37 \%$ cases per year for the less atrophic $H$. pylori-positive cases to $0.53 \%$ cases per year in the severely atrophic $H$. pylori-negative cases [131].

On the issue of acceptability of examinations to patients, Miki et al. conducted a screening by serum pepsinogen in 101892 patients. This indicated 21178 endoscopies, of which 13789 were effectively done (65\%): 125 cancers were diagnosed, $80 \%$ of them at an early stage [137].

Several case-control studies comparing gastric cancer patients with healthy controls, including a range of 84 to 511 cases per study, found statistically significant odds ratios (ORs) for cancer, ranging from $2.24-12.0$ for a PGI level $<50 \mathrm{ng} / \mathrm{mL}$ to an OR of $2.78-10.92$ for a PGI/PGII ratio <3 [138-154].

In diagnostic studies, detection of cancer by serum pepsinogen presented sensitivities of $66.7 \%-84.6 \%$ and specificities of $73.5 \%-81.5 \%$ [155-157], lower mean pepsinogen values compared with non-cancer patients $[120,121,158]$, and a positive correlation with lower PGI/PGII ratio values [159]. Comparative studies of serum pepsinogen and gastric X-ray concluded that the positive predictive value was superior for serum pepsinogen ( $1.4 \%$ vs. $0.8 \%$ ) especially before the age of 50 years [ $160-161]$. Nevertheless, it was noted that most studies came from Japan, and that different laboratory methodologies and different population settings may require cutoff adjustment. Therefore, the term "low level of pepsinogens" was preferred over a defined cutoff value.

\subsubsection{Additional diagnostic factors}

11. Family history of gastric cancer should be taken into account in the follow-up of precancerous conditions (evidence level $2++$, recommendation grade $B$ ). (Agree $96 \%$ [vote: a, 58\%; b, $22 \%$; c, $16 \%$;, $4 \%$ ]; $98 \%$ voters stated that they would apply this statement; $100 \%$ of those representing national societies mentioned that it would also be applicable [90\%] or widely applicable [10\%] in their countries.)

12. Even though diverse studies assessed age, gender, and Helicobacter pylori virulence factors as well as host genetic variations, no clinical recommendations can be made for targeted management based on these factors with regard to diagnosis and surveillance (evidence level 4 , recommendation grade $D$ ). (Agree 82\% [vote: a, 42\%; b, 4\%; c, 36\%; d, 14\%; e,2\%; f, 2\%]) It has long been recognized that $10 \%$ of cases of gastric cancer exhibit some kind of familial aggregation. Of these, only $1 \%-3 \%$ are clearly vertically inherited familial syndromes, such as hereditary diffuse gastric gancer [162,163], Lynch syndrome [164, 165], Peutz-Jeghers syndrome [166,167], and familial adenomatous polyposis [168], in which the risk of gastric cancer and carcinogenesis is well established. For the remainder, the significance 
of family history and familial clustering of gastric cancer is not clearly determined. Having a first-degree relative with gastric cancer is a risk factor for gastric cancer with an odds ratio (OR) varying from 2 to 10 in relation to geographic region and ethnicity [169]. A large study from Turkey reported an OR of 10.1 for siblings of gastric cancer patients, although these results were not adjusted for environmental factors [170]. Other European (OR 1.8-3.5), American (OR 2.2) and Asian (OR 1.5-9.9) case-control studies consistently provided corroboration that having a family history of gastric cancer is a risk factor [171 - 178]. Adjustment for environmental factors did not alter the risk. Interestingly, the Lauren intestinal type of gastric cancer was more strongly associated with family history of gastric cancer than the diffuse type $[176,179]$. It is believed that this familial clustering of gastric cancer is due to an inherited genetic susceptibility, shared environmental or lifestyle factors, or a combination of these in different populations. A recent meta-analysis [180] of 11 studies addressed Helicobacter pylori infection and prevalence of premalignant conditions/lesions in first-degree relatives of gastric cancer patients. For the total of 1500 cases and 2638 controls, the pooled OR for cases to have $H$. pylori gastritis was 1.93 (95\% confidence interval [CI] $1.41-2.61)$, and it was $2.20(1.27-3.82)$ for atrophy, and 1.98 (1.36-2.88) for intestinal metaplasia. Altogether, these data show that first-degree relatives of gastric cancer patients have an increased prevalence of $H$. pylori infection and premalignant conditions/lesions, as well as an increased risk for gastric cancer. To the best of our knowledge, there are no studies aiming to assess whether the premalignant conditions/lesions in relatives of a gastric cancer patient progress more rapidly through the carcinogenic cascade to gastric cancer than similar lesions in matched controls in a general population.

Assuming the gene-environment interaction for gastric cancer, multiple risk factors have been linked to the multistep progression from chronic non-atrophic gastritis to atrophic gastritis, intestinal metaplasia, dysplasia, and finally cancer [6].

H. pylori plays a pivotal role in this progression and has been classified as a type 1 carcinogen in 1994 by the World Health Organization (WHO) [181]. It is believed that the combination of a virulent organism in a genetically susceptible host is associated with more severe chronic inflammation and more rapid progression to gastric cancer, at least for Lauren's intestinal type [182-184]. Different strains of $H$. pylori vary in their carcinogenic potential, with those containing virulence factor CagA inducing a high degree of inflammation. A meta-analysis of 16 case - control studies showed that among $H$. pylori-infected individuals, infection with CagA-positive strains further increases the risk for gastric cancer by 1.64 fold [185]. Other bacterial virulence factors, such as the CagA forms encoding multiple EPIYA-C type segments, and strains that harbor VacA signal region type s1 and mid-region $\mathrm{m} 1$ [186] have also been related to an increased risk for gastric cancer. Nevertheless there are no studies addressing the clinical usefulness of genotyping $H$. pylori strains with regard to the management and surveillance of gastric premalignant conditions/lesions.

An immense number of studies have addressed the issue of genes and genetic variations and their implications for gastric carcinogenesis, although their relevance has not always been clear. In the last few years, the role of host genetic interleukin polymorphisms has been widely studied in relation to gastric carcinogenesis. The best characterized are those that play a role in the inflammatory response to $H$. pylori infection and inflammation of the gastric mucosa, leading to mucosal atrophy and progression to gastric cancer. These in particular include IL-1B, IL1-receptor antagonist (IL-1RN), IL8, IL10 and TNF- $\alpha$. Early studies by ElOmar et al. [187] showed an association of gastric cancer risk with the interleukin 1 genotypes IL-1B-511 T, IL-1B-31 T, and the IL1-receptor antagonist type ${ }^{*} 2 /{ }^{*} 2$, with ORs of $2.5,2.6$ and 3.7 for development of gastric cancer among homozygotic carriers of these alleles compared with non-carriers. Results from other studies were inconsistent because of variations in allele frequencies in different ethnic groups, tumor type and location, $H$. pylori infection, methodologies, and quality of studies $[188,189]$. Three powered meta-analyses found an association of IL-1B and IL$1 \mathrm{RN}^{*} 2$ risk in Caucasians but not in Asians [190-192] and another study found a null association in both populations [193]. Another recent meta-analysis [189] found an increased cancer risk for IL-RN*2 carriers, a risk that was specific to non-Asian populations and for distal cancers; the analysis restricted for high quality studies or $H$. pylori-positive cases and controls disclosed an association with the carrier and the homozygosity status. Regarding Asian populations, reduced risk was observed with IL1B-31C carrier status (in high quality studies). Caucasian carriers of TNF- $\alpha-308 \mathrm{~A}$ were found to be at an increased risk for gastric cancer in a recent meta-analysis [194]. At present, the heterogeneity of results makes it difficult to translate them into recommendations for daily clinical practice.

\subsection{Surveillance}

\subsubsection{Dysplasia}

13. Patients with low grade dysplasia in the absence of an endoscopically defined lesion should receive follow-up within 1 year after diagnosis. In the presence of an endoscopically defined lesion, endoscopic resection should be considered, to obtain a more accurate histological diagnosis (evidence level $2+$, recommendation grade C). (Agree 98\% [vote: a, 60\%; b, 26\%; c, 13\%; d, $2 \%$ ]; $96 \%$ of voters stated that they would apply this statement; $90 \%$ of those representing national societies mentioned that it would be applicable [80\%] or widely applicable [10\%] in their countries.)

14. For patients with high grade dysplasia in the absence of endoscopically defined lesions, immediate endoscopic reassessment with extensive biopsy sampling and surveillance at 6-month to 1 -year intervals is indicated (evidence level $2+$, recommendation grade C). (Agree 98\% [vote: a, 69\%; b, 17\%; c, $12 \%$; d, 2\%]; $100 \%$ of voters stated that they would apply this statement; $100 \%$ of those representing national societies mentioned that it would be applicable [70\%] or widely applicable [30\%] in their countries.)

As mentioned above, differences exist between studies from the West and from Asia in reported progression rate of severe dysplasia. A large prospective study in China included 546 patients with dysplasia: within 5 years of follow-up, progression rates to gastric cancer were $0.6 \%$ per year for mild dysplasia (now generally called low grade dysplasia), and $1.4 \%$ for severe dysplasia (now generally called high grade dysplasia) [32]. The largest Western study included 7,616 patients with mild to moderate dysplasia, and 562 with severe dysplasia: within 5 years' follow-up, the annual incidence of gastric cancer was $0.6 \%$ for mild to moderate dysplasia, and $6 \%$ for severe dysplasia [28].

High grade dysplasia-associated risk. Most patients harboring lesions classified as high grade dysplasia are at high risk for either synchronous invasive carcinoma or its rapid development [34]. In a cohort of patients with premalignant gastric lesions, approximately $25 \%$ of patients with high grade dysplasia received a diag- 
nosis of gastric cancer within 1 year of follow-up [28]. This finding implies that thorough endoscopic and histological re-evaluation shortly after initial diagnosis is indicated, and resection needs to be considered in the case of endoscopically defined lesions, either through endoscopy (endoscopic mucosal resection) or surgery [45, 195-197].

Low grade dysplasia-associated risk. Gastric cancer risk in patients with low grade dysplasia is similar to or even considerably higher than the risk of cancer after removal of colonic adenomas, or in patients with Barrett's esophagus, or in those with longstanding inflammatory bowel disease [198-200]. In comparison with patients harboring high grade dysplasia, patients with low grade dysplasia seem to show a smaller risk to progress to invasive carcinoma of $7 \%(95 \%$ CI $6 \%-8 \%)[28,29,33-37,42,43,45$, 201-203].

Thus, at least endoscopic surveillance at regular intervals seems to be indicated, although cost-effectiveness requires further evaluation. When repeated endoscopy with surveillance biopsy sampling confirms the presence of low grade dysplasia, continued surveillance is warranted. When low grade dysplasia cannot be confirmed during re-evaluation endoscopy, it is unclear for how long surveillance should be continued.

Of major importance is the fact that low grade and high grade dysplasia may present as endoscopically visible, depressed or elevated lesions [34, 200], but may also present as minute or flat lesions, that may be isolated or multifocal [7]. Thus, the disappearance of dysplasia or its assumed disappearance, as evaluated by successive current videoendoscopy biopsies during follow-up procedures, does not rule out the possible progression to invasive cancer [37, 44, 196, 204].

It seems therefore reasonable to propose high quality endoscopic follow-up for patients with low grade dysplasia [33, 37, 201, 205], expanding this to endoscopic resection of the most severe lesions in some patients [196, 202, 206]. In fact, a histological diagnosis of low grade dysplasia in forceps biopsies, obtained from an endoscopically defined lesion, may be upgraded to a diagnosis of high grade dysplasia or even adenocarcinoma after endoscopic mucosal resection (EMR) [207, 208]. In a Korean patient series such an upgraded diagnosis after EMR occurred in up to $19 \%$ of low grade dysplasia diagnoses on biopsy forceps specimens [208]. However, previously mentioned progression rates of low grade dysplasia in large series seem discrepant with these findings. Moreover, in 3\% to $5 \%$ of gastric neoplasia diagnoses on forceps biopsy tissue, EMR does not confirm this diagnosis [208, 209]. Nevertheless, EMR may be considered in patients with low grade dysplasia with an endoscopically defined lesion, in order to obtain a more accurate histological diagnosis.

\subsubsection{Atrophy or intestinal metaplasia}

15. Endoscopic surveillance should be offered to patients with extensive atrophy and/or intestinal metaplasia (i.e., atrophy and/or intestinal metaplasia in the antrum and corpus) (evidence level $2++$, recommendation grade B). (Agree $94 \%$ [vote: a, $60 \%$; b, $15 \%$; c, $19 \%$; d, $4 \%$; f, $2 \%$ ]; $91 \%$ of voters stated that they would apply this statement; $80 \%$ of those representing national societies mentioned that it would be applicable in their countries.)

16. Patients with extensive atrophy and/or intestinal metaplasia should receive follow-up every 3 years after diagnosis (evidence level 4, recommendation grade D). (Agree $86 \%$ [vote: a, $43 \%$; b, $20 \%$; c, $23 \%$; d, $12 \%$; f, $2 \%$ ]; $90 \%$ of voters stated that they would apply this statement; $80 \%$ of those representing national societies mentioned that it would be applicable [70\%] or widely applicable [10\%] in their countries.)

17. For those patients with mild to moderate atrophy/intestinal metaplasia restricted to the antrum there is no evidence to recommend surveillance (evidence level 4, recommendation grade $D$ ). (Agree 99\% [vote: a, $87 \%$; b, 13\%; c, 9\%; d, 1\%])

As early detection of gastric cancer leads to improved survival, surveillance of premalignant gastric conditions/lesions may be important, as shown in several studies. Rates of progression in patients with atrophic gastritis, and intestinal metaplasia vary between respectively $0 \%$ to $1.8 \%$, and $0 \%$ to $10 \%$ per year. Overall, gastric cancer risk is too low to justify endoscopic surveillance in all patients with atrophic gastritis and intestinal metaplasia. Therefore, additional risk factors for progression towards gastric cancer need to be identified in these categories of patients.

First, the intragastric distribution and extent of intestinal metaplasia has been identified as a risk factor for gastric cancer. Atrophic gastritis tends to show a diffuse intragastric pattern, whereas intestinal metaplasia tends to be multifocal [44]. Several studies have shown that gastric cancer risk increases in patients with extensive intragastric lesions [210-213]. Two forms of extensive intestinal metaplasia have been identified. In the socalled "magenstrasse" or "transitional zones" distribution, intestinal metaplasia is found over the lesser curvature from cardia to pylorus and is especially common in the transitional zones (from cardia to corpus, from corpus to antrum), and in the "diffuse distribution" the gastric mucosa is diffusely replaced by intestinaltype mucosa, except for in the fundic region [214]. These topographical patterns of intestinalization show an increased risk for cancer (odds ratio $[\mathrm{OR}]=5.7[95 \% \mathrm{CI} 1.3-26]$ and $\mathrm{OR}=12.2[2.0-$ 72.9], respectively). To establish the extent of atrophic gastritis and intestinal metaplasia, three methods can be used: endoscopic assessment, histological assessment of biopsy specimens, and serology. In Asian countries the presence and extent of premalignant gastric conditions/lesions are frequently established at endoscopy. For the presence of atrophic gastritis the Kimura classification is used [215]. However, this method requires considerable experience on the part of endoscopists. In addition, biopsy sampling can be used to estimate the intragastric extent of lesions and the severity of atrophic gastritis and intestinal metaplasia can be assessed according to the Sydney System. As has been suggested by the OLGA (operative link for gastritis assessment) and OLGIM (operative link for gastric intestinal metaplasia) classifications, both the intragastric extent and severity of atrophic gastritis and intestinal metaplasia within biopsy samples determines gastric cancer risk. Finally, serologic testing for pepsinogens, gastrin, and $H$. pylori antibodies has great potential for establishing the intragastric extent of atrophic gastritis. Serology identifies individuals at increased risk of progression towards dysplasia and gastric cancer, and is currently used in certain Japanese gastric cancer screening programs to identify patients to whom follow-up should be offered [100].

Secondly, individuals with a positive family history of gastric cancer carry an increased risk of premalignant gastric conditions/lesions, and gastric cancer. The risk of atrophic gastritis in these individuals is approximately seven times higher compared with that of controls [187].

Thirdly, the type of intestinal metaplasia has been suggested as a risk factor for gastric cancer development. In a few studies, type III or incomplete intestinal metaplasia was associated with an increased risk for development of gastric cancer [19, 216, 217]. However, these observations have not been confirmed in other 
studies [218, 219]. Therefore, subtyping of intestinal metaplasia is not recommended for clinical practice.

\subsection{Therapy}

\subsubsection{Eradication of Helicobacter pylori}

18. Helicobacter pylori eradication heals nonatrophic chronic gastritis and it may lead to partial regression of atrophic gastritis (evidence level $1+$, recommendation grade B). (Agree 96\% [vote: a, $70 \%$; b, $16 \%$; c, $10 \%$; d, $4 \%$ ]; $98 \%$ of voters stated they would apply this statement; $90 \%$ of those representing national societies mentioned that it would be applicable [40\%] or widely applicable [50\%] in their countries.)

19. In patients with intestinal metaplasia, $H$. pylori eradication does not appear to reverse intestinal metaplasia but it may slow progression to neoplasia, and therefore it is recommended (evidence level $1+$, recommendation grade B). (Agree $96 \%$ [vote: a, $50 \%$; b, $24 \%$; c, $22 \%$; d, $4 \%$ ]; $100 \%$ of voters stated they would apply this statement; $90 \%$ of those representing national societies mentioned that it would be applicable or widely applicable [30\%] in their countries.)

20. H. pylori eradication is recommended for patients with previous neoplasia after endoscopic or surgical therapy (evidence level $1++$, recommendation grade $A$ ). (Agree $96 \%$ [vote: a, $80 \%$; b, $8 \%$; c, $8 \%$; d, $4 \%$ ]; $96 \%$ of voters stated they would apply this statement; $100 \%$ of those representing national societies mentioned that it would be applicable or widely applicable [50\%] in their countries.)

In rodent models, Helicobacter pylori eradication has been shown to have a prophylactic effect on gastric cancer [220-222].

However, studies on $H$. pylori eradication in humans have shown less consistent results. There is no dispute that $H$. pylori eradication leads to healing of non-atrophic gastritis, but the evidence is not so clear for gastric atrophy and intestinal metaplasia.

A recent randomized study and a meta-analysis showed that in early stages of disease such as chronic gastritis and gastric atrophy without metaplasia, H. pylori eradication markedly improves gastric histology towards normal [223, 224]. Another systematic review also concluded that atrophic gastritis can regress within 1 - 2 years after $H$. pylori eradication [225].

A more recent meta-analysis on this subject suggests that gastric atrophy, however, may be reversible only in the corpus and not in the antrum [226]. The probability of reversal of gastric atrophy appears to be dependent on the extent and topographic location of atrophy [226]; however it is unclear whether the effects of $H$. pylori eradication vary with the location and extent of atrophy. In contrast to gastritis and atrophy, the effect of $H$. pylori eradication on gastric intestinal metaplasia is controversial. Some authors completely refute the idea of reversibility of intestinal metaplasia after $H$. pylori eradication $[227,228]$. A lower $H$. pylori colonization of metaplastic areas may indicate a limited benefit for eradication. Two meta-analyses on this subject also concluded that there is no significant improvement in intestinal metaplasia after $H$. pylori eradication [224, 226]. Nevertheless, in a randomized trial, after 6 years of follow-up, Correa et al. showed that in patients with preneoplastic lesions, effective anti-H. pylori treatment and dietary supplementation with antioxidant micronutrients may interfere with the precancerous process, mostly by increasing the rate of regression of cancer precursor conditions/lesions including intestinal metaplasia [229]. This regression of atrophy and intestinal metaplasia was further confirmed after 12 years of follow-up [230].
Nevertheless, it remains to be proven whether eradication at these stages reduces the risk of cancer.

A large-scale randomized trial in China failed to demonstrate that $H$. pylori eradication led to a significant decrease in the rate of gastric cancer [231]. However, in the same study, considering only the group of patients without preneoplasic conditions/lesions at baseline, the risk of cancer in a period of 7.5 years was reduced after $H$. pylori eradication ( 0 vs. 6 cases, $P=0.02$ ). A subsequent meta-analysis, including four randomized intervention studies with a follow-up ranging from 5 to 12 years comparing H. pylori eradication versus placebo for prevention of gastric cancer, showed a non-statistically significant trend in favor of eradication therapy. Further analysis with inclusion of non-randomized studies with follow-up of 3-8.5 years showed a significant reduction in cancer incidence after eradication [232]. The same authors recently updated their meta-analysis and, in a pooled analysis of 6 studies with a total of 6695 participants followed from 4 to 10 years, they found that the relative risk for gastric cancer following $H$. pylori eradication was 0.65 (95\%CI $0.43-$ 0.98 ) [233]. These authors concluded that while H. pylori eradication seems to reduce gastric cancer, however, that might be relevant in only a subset of participants, probably in the early stages of gastritis (non-atrophic) [232, 233]. Another systematic review also concluded that there is sufficient clinical evidence that $H$. pylori eradication has a role in the prevention of gastric cancer in patients with chronic non-atrophic gastritis and with atrophic gastritis [225]. Indeed, a large prospective study (mean followup of 9.4 years) also suggested that $H$. pylori eradication before the development of intestinal metaplasia is probably more effective in reducing gastric cancer incidence [234].

Moreover, four prospective trials (follow-up range 3-8.5 years) that evaluated the effect of $H$. pylori eradication in patients with premalignant conditions/lesions to the end point of gastric cancer failed to show a significant reduction in cancer risk [230, $231,235,236]$. And, one non-randomized prospective study (mean follow-up 8.6 years) demonstrated a significant reduction of gastric cancer development after successful $H$. pylori eradication in comparison with those with persistent $H$. pylori infection [237]. However, in the same cohort, cancer still developed after 14 years of follow-up in some $H$. pylori-negative patients, suggesting that even after cure of infection, cancer can still develop [238]. Nevertheless, in studies involving patients who had previously undergone endoscopic resection of cancer, the majority of whom had extensive intestinal metaplasia, the risk of cancer was significantly reduced after successful $H$. pylori eradication and in a short period of time (3 years) [239, 240].

Indeed, at least, $H$. pylori eradication seems to decrease the progression of gastric intestinal metaplasia [235, 241, 242]. However, even after successful $H$. pylori eradication, gastric cancer still develops in the context of intestinal metaplasia [234, 238]. Therefore, the evidence is not clear regarding whether $H$. pylori eradication will reduce the risk of cancer in patients with extensive intestinal metaplasia, although there is some evidence that it slows progression.

Based on these literature data, the consensus panel came to the view that $H$. pylori eradication should be considered in a caseby-case approach in patients with intestinal metaplasia, taking into account the extent of metaplasia and the degree of $H$. pylori colonization.

$H$. pylori eradication is recommended by several societies and guidelines for gastric cancer patients who undergo subtotal gastrectomy [243-246]. Indeed, eradication of H. pylori in patients 
with previous endoscopic resection of tumors decreases the rate of occurrence of new tumors and the severity of intestinal metaplasia [240]. These results were confirmed in a multicenter randomized control trial [239]. In this open-label study, 272 patients were allocated for eradication or no eradication, with similar baseline characteristics in both groups; after 3 years of followup, 24 metachronous lesions had developed in the non-eradication group compared with 9 new lesions in the eradication group $(P<0.01)$. Another study showed that $H$. pylori eradication in this high risk population was a cost-effective strategy [247]. All these studies showed this protective effect after a short period of time (3 years).

Concerning the effect of $H$. pylori eradication on the progression of gastric dysplasia, the data are scarce and contradictory [229, $230,236]$. So far, most of the evidence suggests that dysplastic lesions are not affected by eradication. However, patients with dysplasia may benefit from eradication because of a decreased incidence of metachronous lesions.

Taking these considerations together, in patients with a previous history of gastric cancer, including dysplasia, H. pylori eradication is strongly recommended.

\subsubsection{Additional measures}

21. Currently, the use of cyclooxgenase-2 (COX-2) inhibitors cannot be supported as an approach to decrease the risk of progression of gastric precancerous lesions (evidence level $1+$, recommendation grade B). (Agree $96 \%$ [vote: a, $50 \%$; b, $20 \%$; c, $26 \%$; d, $2 \%$; e, $2 \%]$ )

22. The use of dietary supplementation with antioxidants (ascorbic acid and beta-carotene) cannot be supported as a therapy to reduce the prevalence of atrophy or intestinal metaplasia (evidence level $1+$, recommendation grade B). (Agree $96 \%$ [vote: a, $63 \%$; b, $14 \%$; c, $19 \%$; d, $4 \%$ ])

Meta-analyses of observational studies demonstrated that longterm non-selective inhibition of cyclooxygenase (COX), through the use of non-steroidal anti-inflammatory drugs (NSAIDs), is an effective chemopreventive strategy for gastric cancer development [248, 249].

The available literature on the efficacy of the use of COX-2 inhibitors to prevent the progression of gastric precancerous lesions is restricted to five clinical studies conducted exclusively in Asian populations. The overall evidence regardless of type of drug used is inconsistent. Apart from one well-designed placebo-controlled randomized controlled trial (RCT) [250] the evidence suggesting a preventive effect of these chemopreventive agents on precancerous lesions outcome is drawn from low quality studies, comprising one small RCT [251], one pilot study [252] and two prospective cohorts $[253,254]$. These were conducted in very heterogeneous populations (first-degree relatives of gastric cancer patients, dyspeptic patients with rheumatologic diseases, early gastric cancer patients, etc) that compromise the generalizability and interpretation of data.

Three selective COX-2 inhibitors were considered: rofecoxib, etodolac, and celecoxib. Rofecoxib for 2 years in an RCT did not have a significant benefit in terms of intestinal metaplasia regression after Helicobacter pylori eradication [250]. Yanaoka et al. reported a higher metachronous cancer incidence in patients treated with $300 \mathrm{mg} /$ day of etodolac, after a mean follow-up period of 4.2 years. Interestingly, no significant change in the extent of precancerous conditions/lesions was observed despite etodolac treatment [253].
Most studies focused on whether celecoxib, a selective COX-2, could decrease the severity of gastric precancerous conditions/lesions following $H$. pylori eradication. In patients receiving celecoxib in a small randomized trial, a $67 \%$ improvement in gastric precancerous lesion histology was observed $(P<0.001$, vs. $16.1 \%$ in the placebo group) after 12 weeks [251]. In a pilot study, following 8 weeks of intervention, in $29 \%$ of patients a complete regression of persistent intestinal metaplasia was noticed in those with confirmed $H$. pylori eradication [252]. Furthermore, in those patients without complete regression an improvement in intestinal metaplasia severity was noticed $(P<0.007)$ [252]. Additionally, Yang et al. [254], observed that dyspeptic chronic users of celecoxib for rheumatologic diseases presented a higher regression rate of intestinal metaplasia than non-NSAID users ( $42 \%$ vs. $20 \%$; relative risk $[R R]=2.9,95 \%$ CI $1.88-6.91$ ) but only after $H$. pylori eradication.

Therefore, there is some evidence supporting the involvement of celecoxib in the regression of gastric precancerous conditions/lesions, namely intestinal metaplasia, that could motivate the design of larger RCTs with longer follow-up. Furthermore, regular use of non-selective NSAIDs, including aspirin, has been associated with a decreased risk for gastric cancer development, as observed in a recent large retrospective cohort [255] and meta-analyses [249]. Further prospective clinical trials are needed to address the effects of these non-specific COX inhibitors on the progression of gastric lesions.

Three chemoprevention trials specifically designed to evaluate the effects of antioxidant vitamin supplementation on gastric precancerous lesions, have been reported $[229,136,156]$. These randomized double-blind placebo-ontrolled trials, conducted in populations at high risk for gastric cancer, presented conflicting results and their quality is compromised by significant loss to follow-up/withdrawal observed in two of the studies [229, 256].

Correa et al. [229] reported that patients randomized to single active intervention with ascorbic acid ( $1 \mathrm{~g}$ twice daily), beta-carotene $(30 \mathrm{mg} /$ day) or anti-H. pylori therapy were three times more likely to show an improvement in the histology of their lesions after a 6-year follow-up period. However, this antioxidant benefit disappeared after a further 6 years with no vitamin supplementation, as shown in a re-evaluation at 12 years after the inception of the study [230].

In contrast, a long-term trial in Linqu County, Shandong, China reported no favorable effect on the prevalence of gastric precancerous conditions/lesions after 7.2 years of intervention with vitamin supplements (capsule with $250 \mathrm{mg}$ ascorbic acid, $100 \mathrm{IU}$ vitamin E, and 37.5 $\mu \mathrm{L}$ selenium, twice daily) [236]. Similarly, Plummer et al. [256], in a study involving patients randomized to receive either vitamins (capsule with $250 \mathrm{mg}$ ascorbic acid, $200 \mathrm{mg}$ vitamin E, and $6 \mathrm{mg}$ beta-carotene/thrice daily) or placebo for 3 years, did not observe any significant association between vitamin supplementation and the progression/regression of gastric precancerous conditions/lesions.

These studies were carried out in populations with a high incidence of gastric cancer, in Columbia, Venezuela and China [229, $236,256]$. It is as yet unclear to what extent these results can be generalized to populations with a low incidence of gastric cancer. 


\subsection{Cost-effectiveness}

23. After endoscopic resection of early gastric cancer, Helicobacter pylori eradication is cost-effective (evidence level $1+$, recommendation grade B). (Agree $100 \%$ [vote: a, $79 \%$; b, 14\%; c, 7\%])

24. Currently available evidence does not allow an accurate estimation of the cost-effectiveness of surveillance for premalignant gastric conditions worldwide (evidence level $2+$, recommendation grade C). (Agree $98 \%$ [vote: a, $41 \%$; b, $16 \%$; c, $41 \%$; d, $2 \%]$ )

Most of the studies on cost-effectiveness of Helicobacter pylori eradication for gastric cancer prevention report on models with a population screening scenario, which is outside the scope of this manuscript. Only a few studies dealt with the issue of surveillance after an incidental diagnosis of a gastric premalignant condition/lesion. Most of these studies compared strategies of screening for and treating $H$. pylori versus no screening from the public healthcare provider's perspective; used estimates from systematic reviews of the literature; and conducted sensitivity analyses with results that were consistent in most strategies. Despite involving populations with very different gastric cancer risks, and also the use of diverse models, all studies concluded that the screening option is cost-effective compared with no screening [257-269].

Concerning the possibility of $\mathrm{H}$. pylori eradication after endoscopic mucosal resection (EMR) of a gastric precancerous lesion, Shin et al. [247] developed a Markov model based on a randomized clinical trial conducted by Fukase et al. [239] precisely on this topic. They used a very wide set of clinical health estimates derived from an extensive search of the literature, and costs were based on the perspective of the Korean public healthcare provider. The results showed that in the base-case assumptions, H. pylori eradication was less costly than no eradication (US\$ 29 780 versus 30 594) and also provided more benefits (mean life expectancy of 13.60 versus 13.55). Thus, treatment of 10000 persons would lead to a net saving of US\$ 814200 and around 50 life-years saved (LYS) would be gained. This strategy was dominant (less costly and more effective) but the usual calculation of the ICER (incremental cost-effectiveness ratio) value was not performed. By conducting one-way and three-way sensitivity analyses, the authors confirmed the robustness of the model, with a dominant ICER conclusion for the strategy of eradication in almost every scenario or providing very cost-effective values (always below US\$ 3852 per LYS).

Concerning the cost-effectiveness of secondary surveillance of incidentally detected precancerous conditions/lesions, studies in the published literature provide conflicting results, mainly due to different estimates for lesion progression to dysplasia or cancer. Yeh et al. [270] compared several strategies, from neither surveillance nor treatment to surveillance of various precancerous gastric conditions/lesions at several frequencies followed by treatment with endoscopic mucosal resection (EMR) or surgery. The model was cost-effective for men over 50 years with dysplasia treated by EMR with annual surveillance (cost per quality-adjusted life-year [QALY] US\$ 39 800), but not for patients with intestinal metaplasia (cost per QALY US\$ 544500 for surveillance every 10 years). Hassan et al. [271], using a model for the American population, revealed an incremental cost-effectiveness ratio above $\$ 70000$ per life-year saved for an yearly endoscopy versus no surveillance in patients with intestinal metaplasia, while in a model derived from a Portuguese cohort, Dinis-Ribeiro et al. [136] obtained a cost of only €1868 per QALY in a protocol of yearly magnification chromoendoscopy and pepsinogen measurement.

These conflicting results might arise from very different estimates of the yearly rates for progression of conditions $(0.00-$ $0.012 \%$ per year for dysplasia to invasive cancer in the study of Yeh et al. [270]; 0.18\% for intestinal metaplasia to cancer in Hassan et al. [271]; and $12.8 \%-56.0 \%$ for intestinal metaplasia to dysplasia in the study by Dinis-Ribeiro et al. [136]), and might also arise from the differing cost estimates included in the models (cost per endoscopy of US\$ 871 versus US\$ 358 in the studies by Yeh at al. and Hassan et al., respectively [270, 271]). Moreover, no study except that of Dinis-Ribeiro et al. [136] considered different stages of premalignant gastric conditions/lesions.

\section{RESEARCH AGENDA}

$\nabla$

The extensive examination of the literature and the discussion within the consensus panel led to the research agenda described below, with the possibility of a review in 3 to 5 years.

- Reliability studies for histopathological staging systems for precancerous conditions and for endoscopic features

- Large multicenter cohort studies to derive and validate clinical decision rules addressing the value of variables other than the phenotype of lesion extent, such as age, gender, Helicobacter pylori virulence factors, and genetic profiles

- Large multicenter cohort studies to further clarify stages involved in gastric carcinogenesis, such as the elucidation of the role of spasmolytic polypeptide-expressing metaplasia (SPEM)

- Standardization and validation of endoscopic features with new endoscopic technologies, and randomized trials to address the benefit per-patient in this setting (diagnosis of intestinal metaplasia and atrophy in corpus; and diagnosis of superficial lesions)

- Further clarification of the role of H. pylori eradication and other therapies in prevention of gastric cancer

- Observational and/or decision-analysis studies addressing follow-up intervals and cost-benefit of these strategies

- Studies to address methodologies and target populations for the screening of these lesions in Western countries.

\section{ACKNOWLEDGMENTS}

$\nabla$

These guidelines were made possible through the financial support of the European Society of Gastrointestinal Endoscopy (ESGE) and the Sociedade Portuguesa de Endoscopia Digestiva (SPED). Olympus (Europe), Casen-Fleet (Portugal) and Angelini (Portugal) gave educational grants to ESGE and SPED. We would also like to acknowledge Eng. Jorge Jacome for his support through MedQuest development; and the Secretariats of ESGE (Hilary Hamilton and Nicola Oremus) and SPED (Maria José Ilharco).

\section{APPENDIX}

$\nabla$

All contributors are listed below in alphabetic order, according to their role (Working Group, as national representative, or as an individual), and their participation in the Porto meeting $\left({ }^{*}\right.$ indicates those who voted online only, and not at the Porto meeting). 
Panel of Experts or Young Investigators (Working Group) Miguel Areia, Gastroenterology Department, Portuguese Oncology Institute; Fátima Carneiro, European Society of Pathology, Porto Faculty of Medicine, Serviço de Anatomia Patológica, Porto , Portugal; Annemarie de Vries, Erasmus MC University Medical Center Rotterdam, Gastroenterology and Hepatology, Rotterdam, The Netherlands; Mário Dinis-Ribeiro, Servico de Gastrenterologia, Instituto Portugues de Oncologia Francisco Gentil, Porto, Portugal; Jean-Marc Dumonceau, Départment de Gastroénterologie et d'Hépatopancréatologie, H.U.G. Hôpital Cantonal, Geneve, Switzerland; *Arzu Ensari, Department of Pathology, Ankara University Medical School, Turkey; Ernst J. Kuipers, Department of Gastroenterology and Hepatology, Erasmus MC, Rotterdam, The Netherlands; Guilherme Macedo, IPATIMUP, Porto, Portugal; Jose Carlos Machado, Department of Gastroenterology, Hospital de S.João/Porto Faculty of Medicine, Portugal; Peter Malfertheiner, Klinik der Gasroenterologie, Hepatologie und Infektologie, Otto von Guericke Universität Magdeburg, Germany; Ricardo Marcos-Pinto, Gastroenterology Department, Centro Hospitalar do Porto, Portugal; Tamara Matysiak-Budnik, Service d'HépatoGastroentérologie, Hôtel Dieu, CHU de Nantes, France; Francis Megraud, Inserm U853 and Université Bordeaux, Laboratoire de Bacteriologie, Bordeaux, France; Kazumasa Miki, Japan Research Foundation of Prediction, Diagnosis and Therapy for Gastric Cancer (JRF PDT GC), Tokyo, Japan; Matilde Monteiro-Soares CINTESIS, Porto Faculty of Medicine, Portugal; Anthony O'Connor, AMNCH/TCD, Adelaide and Meath Hospital/Trinity College, Dublin Tallagh, Ireland; Colm O'Morain, Department of Gastroenterology, Adelaide and Meath Hospital, Dublin, Ireland; Richard Peek, Division of Gastroenterology, Vanderbilt University School of Medicine, Nashville, USA; Carina Pereira, Grupo de Oncologia Molecular, Instituto Português de Oncologia do Porto FG, EPE, Porto, Portugal; Pedro Pimentel-Nunes, Servico de Gastrenterologia, IPO-Porto, Portugal, and Department of Physiology, Cardiovascular Research and Development Unit, Medical Faculty, Porto, Portugal; Thierry Ponchon, Hopital Edouard Herriot, Department of Digestive Diseases, Lyon, France; Björn Rembacken, Centre for Digestive Diseases, The General Infirmary at Leeds, UK; Ari Ristimaki, Department of Pathology, HUSLAB and Haartman Institute, Helsinki University Central Hospital and University of Helsinki, Helsinki, Finland.

National representatives Gieri Cathomas (Switzerland, pathology), Head of the Cantonal Institute for Pathology, President Swiss Society of Gastrointestinal Pathology, Cantonal Institute for Pathology, Liestal, Switzerland; Evgeny D. Fedorov (Russia), Russia State Medical University, Moscow University Hospital; Pedro Manuel Narra de Figueiredo (Portugal), Hospitais da Universidade de Coimbra, Serviço de Gastrenterologia, Coimbra, Portugal; Adrian Goldis (Romania), Clinic of Gastroenterology Algomed, Timisoara, Romania; Marcis Leja (Latvia), University of Latvia, Latvian Society of Gastroenterology, Hospital Linezers, Riga, Latvia; Markus Moehler (Germany), 1. Medizinische Klinik und Poliklinik der Johannes-Gutenberg Universität Mainz, Germany; Emil Plesea (Romania, pathology), Department of Pathology, University of Medicine and Pharmacy, Craiova, Romania; *Jacques Bergman (The Netherlands), Department of Gastroenterology and Hepatology, Academic Medical Center Amsterdam, The Netherlands; *Waseem Hamoudi (Jordan), Jordanian Society of Gastroenterology, Amman, Jordan.

As individuals Raquel Almeida, IPATIMUP, Porto, Portugal; Bruno Annibale, Dipartimento Medico-chirurgico di scienze cliniche, Tecnobiomediche e medicina traslazionale, Section of Gastroen- terology, Rome, Italy; Luís Azevedo Lobo, Gastroenterology Department, Pedro Hispano Hospital, ULS Matosinhos, Senhora da Hora, Portugal; Yasemin Hatice Balaban, Hacettepe University, Gastroenterology Unit, Ankara, Turkey; Alina Boeriu, Gastroenterology Department, University of Medicine, Targu Mures, Romania; Alain Burette, Gastroenterology Department, CHIREC, Brussels, Belgium; Anne Courillon Mallet, Service Hépato-gastroentérologie, Centre Hospitalier de Villeneuve St Georges, Villeneuve St Georges, France; Leonor David, IPATIMUP, Porto, Portugal; Jean-Charles Delchier, Service d'hépatogastroentérologie, Hôpital Henri Mondor, Créteil, France; Ecaterina Daniela Dobru, Gastroenterology Department, University of Medicine and Pharmacy, TG. Mures, Romania; Carlos Fernandes, C. H. Vila Nova de Gaia/Espinho, Portugal; Michel Kahaleh, Division of Gastroenterology/Hepatology, University of Virginia Health System, Charlottesville, USA; Sergey Kashin, Yaroslavl Regional Cancer Hospital, Yaroslavl, Russia; Rafael Lomba-Viana, Porto, Portugal; Nuno Lunet, University of Porto Medical School, Department of Clinical Epidemiology, Predictive Medicine and Public Health, Porto, Portugal; Kirill Marakhouski, Minsk, Belarus; Luis Moreira-Dias, Instituto Português De Oncologia Do Porto, Serviço De Gastrenterologia, Porto, Portugal; Carlos Noronha Ferreira, Serviço de Gastrenterologia e Hepatologia, Hospital de Santa Maria-Centro Hospitalar Lisboa Norte, Lisbon, Portugal; Teresa Pinto Pais, Portugal; Antonio Rollán, Gastroenterology Department, Clinica Alemana, Santiago, Chile; Ana Sadio, IPATIMUP, Porto, Portugal; Carlos Figueiredo Costa Santos, Casa Saude Boavista, Porto, Portugal; *Joao Santos Barbosa, Lisbon, Portugal; *Kent-Man Chu, Department of Surgery, The University of Hong Kong, Queen Mary Hospital, Pokfulam, Hong Kong; *Giancarlo D'Ambra, Rome, Italy; *Pierre Ellul, Mater Dei Hospital, Sliema, Malta; *Nicole van Grieken, Department of Pathology, VU University Medical Center, Amsterdam, The Netherlands; * Dominique Lamarque, Service Hépato-Gastroentérologie, Oncologie digestive, Hôpital Ambroise Paré, Boulogne-Billancourt, France; *Akram Ajeel Najeeb, Medical City, Bab Al-Mudhaam, Baghdad, Iraq.

\section{NOTE}

$\nabla$

These guidelines represent a consensus of best practice based on the available evidence at the time of preparation. They may not apply in all situations and should be interpreted in the light of specific clinical situations and resource availability. Further controlled clinical studies may be needed to clarify aspects of these statements, and revision may be necessary as new data appear. Clinical consideration may justify a course of action at variance to these recommendations. These guidelines are intended to be an educational device to provide information that may assist endoscopists in providing care to patients. They are not rules and should not be construed as establishing a legal standard of care or as encouraging, advocating, requiring, or discouraging any particular treatment.

\section{Competing interests: None.}

Department of Gastroenterology, Portuguese Oncology Institute of Porto, Portugal

Department of Gastroenterology, Portuguese Oncology Institute of Coimbra, Portugal

${ }^{3}$ Department of Gastroenterology and Hepatology, Erasmus MC, Rotterdam, The Netherlands

${ }^{4}$ Department of Gastroenterology, Centro Hospitalar do Porto, Portugal 
${ }^{5}$ Centre for Research in Health Technologies and Information Systems (CINTESIS), Medical Faculty, Porto, Portugal

${ }^{6}$ Institute of Biomedical Sciences, University of Porto (ICBAS/UP), Porto, Portugal

AMNCH/TCD, Adelaide and Meath Hospital/Trinity College, Gastroenterology Department, Dublin, Ireland

Molecular Oncology Research Group, Portuguese Oncology Institute of Porto, Portugal

${ }^{9}$ Department of Pathology, Ankara University Medical School, Ankara, Turkey

${ }^{10}$ Département de Gastroénterologie et d'Hépatopancréatologie, H.U.G. Hôpital Cantonal, Geneve, Switzerland

${ }^{11}$ Institute of Molecular Pathology and Immunology of the University of Porto (IPATIMUP), Porto, Portugal

12 Department of Gastroenterology, Centro Hospitalar S. João/Medical Faculty, Porto, Portugal

${ }^{13}$ Klinik der Gasroenterologie, Hepatologie und Infektologie, Otto von Guericke Universität Magdeburg, Magdeburg, Germany

${ }^{14}$ Service d'Hépato-Gastroentérologie, Hôtel Dieu, CHU de Nantes, Nantes, France

15 Inserm U853 \& Université Bordeaux, Laboratoire de Bacteriologie, Bordeaux, France

${ }^{16}$ Japan Research Foundation of Prediction, Diagnosis and Therapy for Gastric Cancer (JRF PDT GC), Tokyo, Japan

${ }^{17}$ Division of Gastroenterology, Vanderbilt University School of Medicine, Nashville, USA

${ }^{18}$ Hôpital Edouard Herriot, Department of Digestive Diseases, Lyon, France

${ }^{19}$ Department of Pathology, HUSLAB and Haartman Institute, Helsinki University Central Hospital and University of Helsinki, Helsinki, Finland.

${ }^{20}$ Genome-Scale Biology, Research Program Unit, University of Helsinki, Helsinki, Finland

${ }^{21}$ Centre for Digestive Diseases, The General Infirmary at Leeds, Leeds, United Kingdom

22 Department of Pathology, Medical Faculty/Centro Hospitalar S. João, Porto, Portugal

\section{References}

1 Correa P. A human model of gastric carcinogenesis. Cancer Res 1988; 48: $3554-3560$

2 Collaboration AGREE. Development and validation of an international appraisal instrument for assessing the quality of clinical practice guidelines: the AGREE project. Qual Saf Health Care 2003; 12: 18-23

3 Atkins D, Best D, Briss PA et al. GRADE Working Group Grading quality of evidence and strength of recommendations. BMJ 2004; 328: 1490

4 Guyatt GH, Oxman AD, Vist GE et al. GRADE working group GRADE: an emerging consensus on rating quality of evidence and strength of recommendations. BMJ 2008; 336: 924-926

5 Harbour R, Miller J. A new system for grading recommendations in evidence-based guidelines. BMJ 2001; 323: 334-336

6 Correa P. Human gastric carcinogenesis: a multistep and multifactorial process - First American Cancer Society Award Lecture on Cancer Epidemiology and Prevention. Cancer Res 1992; 52: 6735-6740

7 Kapadia CR. Gastric atrophy, metaplasia and dysplasia. A clinical perspective. J Clin Gastroenterol 2003; 36: 29-36

8 Carneiro F, Machado JC, David L et al. Current thoughts on the histopathogenesis of gastric cancer. Eur J Cancer Prev 2001; 10: 101 - 102

9 Ihamäki T, Saukkonen M, Siurala M. Long term observation of subjects with normal mucosa and with superficial gastritis: results of 23-27 years follow-up examination. Scand J Gastroenterol 1978; 13: 771 775

10 Ormiston MC, Gear MW, Codling BW. Five year follow-up study of gastritis. J Clin Pathol 1982; 35: 757-760

11 Laurén P. The two histological main types of gastric carcinoma: diffuse and so-called intestinal-type carcinoma. Acta Pathol Microbiol Scand 1965; 64: 31-49

12 Fukao A, Hisamichi S, Ohsato M et al. Correlation between the prevalence of gastritis and gastric cancer in Japan. Cancer Causes Control 1993; 4: 17-20

13 Genta RM. Review article: gastric atrophy and atrophic gastritis-nebulous concepts in search of a definition. Aliment Pharmacol Ther 1998; 12: $17-23$

14 Dixon MF, Genta RM, Yardley JH et al. Classification and grading of gastritis. The updated Sydney System. International Workshop on the Histopathology of Gastritis, Houston 1994. Am J Surg Pathol 1994; 20 : $1161-1181$

15 Misiewicz JJ. The Sydney System: a new classification of gastritis. Introduction. J Gastroenterol Hepatol 1991; 6: 207-208
16 Plummer M, Buiatti E, Lopez G et al. Histological diagnosis of precancerous lesions of the stomach: a reliability study. Int J Epidemiol 1997; 26: $716-720$

17 Filipe MI, Potet F, Bogomoletz WV et al. Incomplete sulphomucin-secreting intestinal metaplasia for gastric cancer. Preliminary data from a prospective study from three centres. Gut 1985; 26: 1319-1326

18 Filipe MI, Barbatis C, Sandey A et al. Expression of intestinal mucin antigens in the gastric epithelium and its relationship with malignancy Hum Pathol 1988; 19: 19-26

19 Silva S, Filipe MI, Pinho A. Variants of intestinal metaplasia in the evolution of chronic atrophic gastritis and gastric alcer. A follow up study. Gut 1990; 31: 1097-1104

20 Reis CA, David L, Correa P et al. Intestinal metaplasia of human stomach displays distinct patterns of mucin (MUC1, MUC2, MUC5AC and MUC6) expression. Cancer Res 1999; 59: $1003-1007$

21 Gutiérrez-González L, Wright NA. Biology of intestinal metaplasia in 2008: more than a simple phenotypic alteration. Dig Liver Dis 2008; 40: $510-522$

22 Correa P. Clinical implications of recent developments in gastric cancer pathology and epidemiology. Semin Oncol 1985; 12: 2-10

23 Genta RM, Rugge M. Gastric precancerous lesions: heading for an international consensus. Gut 1999; 45: 15 - 18

24 Guindi M, Riddell $R H$. The pathology of epithelial pre-malignancy of the gastrointestinal tract. Best Pract Res Clin Gastroenterol 2001; 15 $191-210$

25 Riddell RH. Premalignant and early malignant lesions in the gastrointestinal tract: definitions, terminology and problems. Am J Gastroenterol 1996; 91: 864-872

26 Odze RD, Riddell RH, Bosman FT et al. (ed.) Premalignant lesions of the digestive system. In: Bosman FT, Carneiro F, Hruban RH, Theise ND (ed) WHO Classification of Tumours of the Digestive System. 4: edn. Lyon: IARC Press; 2010

27 Park SY, Jeon SW, Jung MK et al. Long-term follow-up study of gastric intraepithelial neoplasias: progression from low-grade dysplasia to invasive carcinoma. Eur J Gastroenterol Hepatol 2008; 20: 966 - 970

28 de Vries AC, van Grieken NC, Looman CW et al. Gastric cancer risk in patients with premalignant gastric lesions: a nationwide cohort study in the Netherlands. Gastroenterology 2008; 134: 945 -952

29 Yamada $H$, Ikegami $M$, Shimoda $T$ et al. Long-term follow-up study of gastric adenoma/dysplasia. Endoscopy 2004; 36: 390-396

30 Dinis-Ribeiro $M$, Lopes C, da Costa-Pereira A et al. A follow up model for patients with atrophic chronic gastritis and intestinal metaplasia. J Clin Pathol 2004; 57: 177-182

31 Whiting JL, Sigurdsson A, Rowlands DC et al. The long term results of endoscopic surveillance of premalignant gastric lesions. Gut 2002; 50: $378-381$

32 You WC, Li JY, Blot WJ et al. Evolution of precancerous lesions in a rural Chinese population at high risk of gastric cancer. Int J Cancer 1999; 83: 615-619

33 Kokkola A, Haapiainen $R$, Laxén $F$ et al. Risk of gastric carcinoma in patients with mucosal dysplasia associated with atrophic gastritis: a follow-up study. J Clin Pathol 1996; 49: 979-984

34 Rugge M, Farinati F, Baffa R et al. Gastric epithelial dysplasia in the natural history of gastric cancer: a multicenter prospective follow-up study. Interdisciplinary Group on Gastric Epithelial Dysplasia. Gastroenterology 1994; 107: 1288-1296

35 Bearzi I, Brancorsini D, Santinelli A et al. Gastric dysplasia: a ten-year follow-up study. Pathol Res Pract 1994; 190: 61-68

36 Di Gregorio C, Morandi P, Fante R et al. Gastric dysplasia. a follow-up study. Am J Gastroenterol 1993; 88: 1715-1719

37 Fertitta AM, Comin U, Terruzzi $V$ et al. Clinical significance of gastric dysplasia: a multicenter follow-up study. Gastrointestinal Endoscopic Pathology Study Group. Endoscopy 1993; 25: 265-268

38 Farinati F, Rugge M, Di Mario F et al. Early and advanced gastric cancer in the follow-up of moderate and severe gastric dysplasia patients. A prospective study. I.G.G.E.D. - Interdisciplinary Group on Gastric Epithelial Dysplasia. Endoscopy 1993; 25: $261-264$

39 Rugge M, Farinati F, Di Mario F et al. Gastric epithelial dysplasia: a prospective multicenter follow-up study from the Interdisciplinary Group on Gastric Epithelial Dysplasia. Hum Pathol 1991; 22: 1002 - 1008

40 Rugge $M$, Baffa R, Farinati $F$ et al. Epithelial dysplasia in atrophic gastritis. Bioptical follow-up study. Ital J Gastroenterol 1991; 23: 70 - 73

41 Koch HK, Oehlert M, Oehlert W. An evaluation of gastric dysplasia in the years 1986 and 1987. Pathol Res Pract 1990; 186: 80-84 
42 Lansdown M, Quirke P, Dixon MF et al. High grade dysplasia of the gastric mucosa: a marker for gastric adenocarcinoma. Gut 1990; 31: 977 983

43 Coma del Corral MJ, Pardo-Mindan FJ, Razquin S et al. Risk of cancer in patients with gastric dysplasia. Follow-up study of 67 patients. Cancer 1990; 65: 2078-2085

44 Correa $P$, Haenszel $W$, Cuello $C$ et al. Gastric precancerous process in a high risk population: cohort follow-up. Cancer Res 1990; 50: 4737 4740

45 Saraga EP, Gardiol D, Costa J. Gastric dysplasia. A histological follow-up study. Am J Surg Pathol 1987; 11: $788-796$

46 Andersson $A P$, Lauritsen $K B$, West $F$ et al. Dysplasia in gastric mucosa: prognostic significance. Acta Chir Scand 1987; 153: 29-31

47 Aste $H$, Sciallero S, Pugliese $V$ et al. The clinical significance of gastric epithelial dysplasia. Endoscopy 1986; 18: 174-176

48 Farini $R$, Pagnini $C A$, Farinati $F$ et al. Is mild gastric epithelial dysplasia an indication for follow-up? J Clin Gastroenterol 1983; 5: $307-310$

49 Riddell RH, Goldman H, Ransohoff DF et al. Dysplasia in inflammatory bowel disease: standardized classification with provisional clinical applications. Hum Pathol 1983; 14: 931 - 968

50 Lauwers GY, Shimizu M, Correa P et al. Evaluation of gastric biopsies for neoplasia: differences between Japanese and Western pathologists. Am J Surg Pathol 1999; 23: 511 - 518

51 Lauwers GY, Carneiro F, Graham DY et al. Gastric carcinoma. In: Bosman FT, Carneiro F, Hruban RH, Theise ND (eds.) WHO Classification of tumours of the digestive system. 4: edn. Lyon: IARC Press; 2010: $48-58$

52 Atkins L, Benedict EB. Correlation of gross gastroscopic findings with gastroscopic biopsy in gastritis. N Engl J Med 1956; 254: 641 - 644

53 Bah A, Saraga E, Armstrong $D$ et al. Endoscopic features of Helicobacter pylori-related gastritis. Endoscopy 1995; 27: 593-596

54 Calabrese C, Di Febo G, Brandi G et al. Correlation between endoscopic features of gastric antrum, histology and Helicobacter pylori infection in adults. Ital J Gastroenterol Hepatol 1999; 31: 359-365

55 Carpenter HA, Talley NJ. Gastroscopy is incomplete without biopsy: clinical relevance of distinguishing gastropathy from gastritis. Gastroenterology 1995; 108: 917 - 924

56 Loffeld RJ. Diagnostic value of endoscopic signs of gastritis: with special emphasis to nodular antritis. Neth J Med 1999; 54: 96-100

57 Redéen S, Petersson F, Jönsson KA et al. Relationship of gastroscopic features to histological findings in gastritis and Helicobacter pylori infection in a general population sample. Endoscopy 2003; 35: 946-950

58 Stathopoulos G, Goldberg RD, Blackstone MO. Endoscopic diagnosis of intestinal metaplasia. Gastrointest Endosc 1990; 36: 544-545

59 Eshmuratov A, Nah JC, Kim N et al. The correlation of endoscopic and histological diagnosis of gastric atrophy. Dig Dis Sci 2010; 55: 1364 1375

60 Yan SL, Wu ST, Chen CH et al. Mucosal patterns of Helicobacter pylorirelated gastritis without atrophy in the gastric corpus using standard endoscopy. World J Gastroenterol 2010; 16: 496-500

61 Laine $L$, Cohen $H$, Sloane $R$ et al. Interobserver agreement and predictive value of endoscopic findings for $\mathrm{H}$. pylori and gastritis in normal volunteers. Gastrointest Endosc 1995; 42: 420 - 423

62 Dinis-Ribeiro M, da Costa-Pereira A, Lopes C et al. Magnification chromoendoscopy for the diagnosis of gastric intestinal metaplasia and dysplasia. Gastrointest Endosc 2003; 57: 498 - 504

63 Areia M, Amaro P, Dinis-Ribeiro $M$ et al. External validation of a classification for methylene blue magnification chromoendoscopy in premalignant gastric lesions. Gastrointest Endosc 2008; 67: 1011 - 1018

64 Mouzyka S, Fedoseeva A. Chromoendoscopy with hematoxylin in the classification of gastric lesions. Gastric Cancer 2008; 11: 15-21 discussion 21-22

65 Tanaka K, Toyoda H, Kadowaki S et al. Surface pattern classification by enhanced magnification endoscopy for identifying early gastric cancers. Gastrointest Endosc 2008; 67: 430 - 437

66 Anagnostopoulos GK, Yao K, Kaye P et al. High-resolution magnification endoscopy can reliably identify normal gastric mucosa, Helicobacter pylori-associated gastritis, and gastric atrophy. Endoscopy 2007; 39: $202-207$

67 Gonen C, Simsek I, Sarioglu S et al. Comparison of high resolution magnifying endoscopy and standard videoendoscopy for the diagnosis of Helicobacter pylori gastritis in routine clinical practice: a prospective study. Helicobacter 2009; 14: $12-21$

68 Tahara T, Shibata T, Nakamura $M$ et al. Gastric mucosal pattern by using magnifying narrow-band imaging endoscopy clearly distingui- shes histological and serological severity of chronic gastritis. Gastrointest Endosc 2009; 70: 246-253

69 Bansal A, Ulusarac O, Mathur S et al. Correlation between narrow band imaging and nonneoplastic gastric pathology: a pilot feasibility trial. Gastrointest Endosc 2008; 67: 210-216

70 Kato M, Kaise M, Yonezawa J et al. Magnifying endoscopy with narrowband imaging achieves superior accuracy in the differential diagnosis of superficial gastric lesions identified with white-light endoscopy: a prospective study. Gastrointest Endosc 2010; 72: 523-529

71 Ezoe Y, Muto M, Horimatsu T et al. Magnifying narrow-band imaging versus magnifying white-light imaging for the differential diagnosis of gastric small depressive lesions: a prospective study. Gastrointest Endosc 2010; 71: 477 - 484

72 Kadowaki S, Tanaka K, Toyoda $\mathrm{H}$ et al. Ease of early gastric cancer demarcation recognition: a comparison of four magnifying endoscopy methods. J Gastroenterol Hepatol 2009; 24: 1625-1630

73 Uedo $N$, Ishihara $R$, Iishi $H$ et al. A new method of diagnosing gastric intestinal metaplasia: narrow-band imaging with magnifying endoscopy. Endoscopy 2006; 38: 819-824

74 Okubo M, Tahara T, Shibata T et al. Changes in gastric mucosal patterns seen by magnifying NBI during $\mathrm{H}$. pylori eradication. J Gastroenterol 2011; 46: $175-182$

75 Kaise $M$, Kato $M$, Urashima $M$ et al. Magnifying endoscopy combined with narrow-band imaging for differential diagnosis of superficial depressed gastric lesions. Endoscopy 2009; 41: 310-315

76 Capelle LG, Haringsma J, da Vries AC et al. Narrow band imaging for the detection of gastric intestinal metaplasia and dysplasia during surveillance endoscopy. Dig Dis Sci 2010; 55: 3442 - 3448

77 Alaboudy AA, Elbahrawy A, Matsumoto $S$ et al. Conventional narrowband imaging has good correlation with histopathological severity of Helicobacter pylori gastritis. Dig Dis Sci 2011; 56: 1127-1130

78 Eriksson NK, Färkkilä MA, Voutilainen ME et al. The clinical value of taking routine biopsies from the incisura angularis during gastroscopy. Endoscopy 2005; 37: $532-536$

79 Guarner J, Herrera-Goepfert R, Mohar A et al. Diagnostic yield of gastric biopsy specimens when screening for preneoplastic lesions. Hum Pathol $2003: 34: 28-31$

80 el-Zimaity HM, Graham DY. Evaluation of gastric mucosal biopsy site and number for identification of Helicobacter pylori or intestinal metaplasia: role of the Sydney System. Hum Pathol 1999; 30: 72 - 77

81 Rugge M, Genta RM. Staging and grading of chronic gastritis. Hum Pathol 2005; 36: 228-233

82 Kashin S, Pavlov A, Gono K, Nadezhin A. Endoscopic diagnosis of early gastric cancer and gastric precancerous lesions. In: Pasechnikov VD ed. Gastric cancer: diagnosis, early prevention, and treatment. 1: edn. New York: Nova Science Publishers; XXXHauppauge?XXX 2010: $197-233$

83 Satoh K, Kimura K, Taniguchi Y et al. Biopsy sites suitable for the diagnosis of Helicobacter pylori infection and the assessment of the extent of atrophic gastritis. Am J Gastroenterol 1998; 93: 569-573

84 de Vries AC, Haringsma J, de Vries RA et al. Biopsy strategies for endoscopic surveillance of pre-malignant gastric lesions. Helicobacter 2010; 15: $259-264$

85 Rugge M, Cassaro M, Pennelli $G$ et al. Atrophic gastritis: pathology and endoscopy in the reversibility assessment. Gut 2003; 52: 1387-1388

86 Ricuarte 0 , Gutierrez 0 , Cardona $H$ et al. Atrophic gastritis in young children and adolescents. J Clin Pathol 2005; 58: 1189-1193

87 You WC, Blot WJ, Li JY et al. Precancerous gastric lesions in a population at high risk of stomach cancer. Cancer Res 1993; 53: 1317-1321

88 Dursun M, Yilmaz S, Yükselen V et al. Evaluation of optimal gastric mucosal biopsy site and number for identification of Helicobacter pylori, gastric atrophy and intestinal metaplasia. Hepatogastroenterology 2004; 51: $1732-1735$

89 el-Zimaity HM, al-Assi MT, Genta RM et al. Confirmation of successful therapy of Helicobacter pylori infection: number and site of biopsies or a rapid urease test. Am J Gastroenterol 1995; 90: 1962 - 1964

90 el-Zimaity HM, Ota H, Graham DY et al. Patterns of gastric atrophy in intestinal type gastric carcinoma. Cancer 2002; 94: 1428-1436

91 el-Zimaity HM, Ramchatesingh J, Saeed MA et al. Gastric intestinal metaplasia: subtypes and natural history. J Clin Pathol 2001; 54: 679 683

92 Rugge M, Correa P, Di Mario F et al. OLGA staging for gastritis: a tutorial Dig Liver Dis 2008; 40: 650-658

93 Rugge M, Genta RM OLGA groupe Staging gastritis: an international proposal. Gastroenterology 2005; 129: 1807-1808 
94 Rugge M, Meggio A, Pennelli G et al. Gastritis staging in clinical practice: the OLGA staging system. Gut 2007; 56: 631-636

95 Satoh $K$, Osawa $H$, Yoshizawa $M$ et al. Assessment of atrophic gastritis using the OLGA system. Helicobacter 2008; 13: 225-229

96 Rugge M, de Boni M, Pennelli $G$ et al. Gastritis OLGA-staging and gastric cancer risk: a twelve year clinico-pathological follow-up study. Aliment Pharmacol Ther 2010; 31: 1104-1111

97 el-Zimaity HM, Graham DY, al-Assi MT et al. Interobserver variation in the histopathological assessment of Helicobacter pylori gastritis. Hum Pathol 1996; 27: $35-41$

98 Capelle LG, de Vries AC, Haringsma J et al. The staging of gastritis with the OLGA system by using intestinal metaplasia as an accurate alternative for atrophic gastritis. Gastrointest Endosc 2010; 71: 1150 - 1158

99 Guarner J, Herrera-Goepfert R, Mohar A et al. Interobserver variability in application of the revised Sydney classification for gastritis. Hum Pathol 1999; 30: 1431 - 1434

100 Dinis-Ribeiro M, Yamaki G, Miki K et al. Meta-analysis on the validity of pepsinogen test for gastric carcinoma, dysplasia or chronic atrophic gastritis screening. J Med Screen 2004; 11: 141 - 147

101 Graham DY, Nurgalieva ZZ, El-Zimaity HM et al. Noninvasive versus histologic detection of gastric atrophy in a Hispanic population in North America. Clin Gastroenterol Hepatol 2006; 4: 306-314

102 Haj-Sheykholeslami A, Rakhshani N, Amirzargar A et al. Serum pepsinogen I, pepsinogen II, and gastrin 17 in relatives of gastric cancer patients: comparative study with type and severity of gastritis. Clin Gastroenterol Hepatol 2008; 6: 174-179

103 Hartleb $M$, Wandzel $P$, Waluga $M$ et al. Non-endoscopic diagnosis of multifocal atrophic gastritis; efficacy of serum gastrin-17, pepsinogens and Helicobacter pylori antibodies. Acta Gastroenterol Belg 2004; 67: 320-326

104 Iijima K, Abe Y, Kikuchi R et al. Serum biomarker tests are useful in delineating between patients with gastric atrophy and normal, healthy stomach. World J Gastroenterol 2009; 15: 853-859

105 Inoue M, Kobayashi S, Matsuura A et al. Agreement of endoscopic findings and serum pepsinogen levels as an indicator of atrophic gastritis. Cancer Epidemiol Biomarkers Prev 1998; 7: 261 - 263

$106 \mathrm{Kim} \mathrm{HY,} \mathrm{Kim} \mathrm{N,} \mathrm{Kang} \mathrm{JN} \mathrm{et} \mathrm{al.} \mathrm{Clinical} \mathrm{meaning} \mathrm{of} \mathrm{pepsinogen} \mathrm{test} \mathrm{and}$ Helicobacter pylori serology in the health check-up population in Korea. Eur J Gastroenterol Hepatol 2009; 21: 606 -612

107 Knight T, Wyatt J, Wilson A et al. Helicobacter pylori gastritis and serum pepsinogen levels in a healthy population: development of a biomarker strategy for gastric atrophy in high risk groups. Br J Cancer 1996; 73: 819-824

108 Leja M, Kupcinkas L, Funka K et al. The validity of a biomarker method for indirect detection of gastric mucosal atrophy versus standard histopathology. Dig Dis Sci 2009; 54: 2377-2384

109 Ley C, Mohar A, Guarner J et al. Screening markers for chronic atrophic gastritis in Chiapas, Mexico. Cancer Epidemiol Biomarkers Prev 2001; 10: $107-112$

110 Nardone G, Rocco A, Staibano $S$ et al. Diagnostic accuracy of the serum profile of gastric mucosa in relation to histological and morphometric diagnosis of atrophy. Aliment Pharmacol Ther 2005; 22: 11391146

111 Pasechnikov VD, Chukov SZ, Kotelevets SM et al. Invasive and non-invasive diagnosis of Helicobacter pylori-associated atrophic gastritis: a comparative study. Scand J Gastroenterol 2005; 40: 297-301

112 Ricci C, Vakil N, Rugge $M$ et al. Serological markers for gastric atrophy in asymptomatic patients infected with Helicobacter pylori. Am J Gastroenterol 2004; 99: 1910-1915

113 Rollan A, Ferreccio C, Gederlini A et al. Noninvasive diagnosis of gastric mucosal atrophy in an asymptomatic population with high prevalence of gastric cancer. World J Gastroenterol 2006; 12: 7172 - 7178

114 Sierra R, Une C, Ramírez Vet al. Association of serum pepsinogen with atrophic body gastritis in Costa Rica. Clin Exp Med 2006; 6: 72 - 78

115 Sitas F, Smallwood R, Jewell D et al. Serum anti-Helicobacter pylori IgG antibodies and pepsinogens $A$ and $C$ as serological markers of chronic atrophic gastritis. Cancer Epidemiol Biomarkers Prev 1993; 2: 119123

116 Storskrubb T, Aro P, Ronkainen J et al. Serum biomarkers provide an accurate method for diagnosis of atrophic gastritis in a general population: the Kalixanda study. Scand J Gastroenterol 2008; 43: 1448 1455

117 Sun $L P$, Gong $Y H$, Wang $L$ et al. Serum pepsinogen levels and their influencing factors: a population-based study in 6990 Chinese from North China. World J Gastroenterol 2007; 13: 6562-6567
$118 W u$ KC, Li HT, Qiao TD et al. Diagnosis of atrophic body gastritis in Chinese patients by measuring serum pepsinogen. Chin J Dig Dis 2004; 5: $22-27$

119 Väänänen $H$, Vauhkonen $M$, Helske $T$ et al. Non-endoscopic diagnosis of atrophic gastritis with a blood test. Correlation between gastric histology and serum levels of gastrin-17 and pepsinogen I: a multicentre study. Eur J Gastroenterol Hepatol 2003; 15: 885-891

$120 \mathrm{Cao} Q$ Ran ZH, Xiao SD. Screening of atrophic gastritis and gastric cancer by serum pepsinogen, gastrin-17 and Helicobacter pylori immunoglobulin G antibodies. J Dig Dis 2007; 8: 15-22

121 Chung HW, Kim JW, Lee JH et al. Comparison of the validity of three biomarkers for gastric cancer screening: carcinoembryonic antigen, pepsinogens, and high sensitive C-reactive protein. J Clin Gastroenterol 2009; 43: 19-26

122 Kiyohira $K$, Yoshihara $M$, Ito $M$ et al. Serum pepsinogen concentration as a marker of Helicobacter pylori infection and the histologic grade of gastritis: evaluation of gastric mucosa by serum pepsinogen levels. J Gastroenterol 2003; 38: $332-338$

123 Oksanen A, Sipponen P, Miettinen A et al. Evaluation of blood tests to predict normal gastric mucosa. Scand J Gastroenterol 2000; 35: 791 795

124 Di Mario F, Cavallar LG, Moussa AM et al. Usefulness of serum pepsinogens in Helicobacter pylori chronic gastritis: relationship with inflammation, activity, and density of the bacterium. Dig Dis Sci 2006 51: $1791-1795$

125 Kreuning J, Lindeman J, Biemond I et al. Serological parameters in assessment of degree of gastritis in healthy volunteers. Dig Dis Sci 1995; 40: 609-614

126 Con SA, Con-Wong R, Con-Chin GR et al. Serum pepsinogen levels, Helicobacter pylori CagA status, and cytokine gene polymorphisms associated with gastric premalignant lesions in Costa Rica. Cancer Epidemiol Biomarkers Prev 2007; 16: 2631 - 2636

127 Dinis-Ribeiro $M$, da Costa-Pereira A, Lopes $C$ et al. Validity of serum pepsinogen $\mathrm{I} / \mathrm{II}$ ratio for the diagnosis of gastric epithelial dysplasia and intestinal metaplasia during the follow-up of patients at risk for intestinal-type gastric adenocarcinoma. Neoplasia 2004; 6: 449-456

128 Urita $Y$, Hike K, Torii $N$ et al. Serum pepsinogens as a predicator of the topography of intestinal metaplasia in patients with atrophic gastritis. Dig Dis Sci 2004; 49: 795 - 801

129 de Vries AC, Haringsma J, de Vries RA et al. The use of clinical, histologic, and serologic parameters to predict the intragastric extent of intestinal metaplasia: a recommendation for routine practice. Gastrointest Endosc 2009; 70: 18-25

130 Watabe H, Mitsushima T, Yamaji Yet al. Predicting the development of gastric cancer from combining Helicobacter pylori antibodies and serum pepsinogen status: a prospective endoscopic cohort study. Gut 2005; 54: $764-768$

131 Yamaji $Y$, Watabe $H$, Yoshida $H$ et al. High-risk population for gastric cancer development based on serum pepsinogen status and lifestyle factors. Helicobacter 2009; 14: $81-86$

132 Yanaoka K, Oka M, Mukoubayashi C et al. Cancer high-risk subjects identified by serum pepsinogen tests: outcomes after 10 -year follow-up in asymptomatic middle-aged males. Cancer Epidemiol Biomarkers Prev 2008; 17: 838-845

133 Yanaoka K, Oka M, Yoshimura $\mathrm{N}$ et al. Risk of gastric cancer in asymptomatic, middle-aged Japanese subjects based on serum pepsinogen and Helicobacter pylori antibody levels. Int J Cancer 2008; 123: 917 926

134 Ohata H, Kitauchi S, Yoshimura N et al. Progression of chronic atrophic gastritis associated with Helicobacter pylori infection increases risk of gastric cancer. Int J Cancer 2004; 109: 138-143

135 Oishi $Y$, Kiyohara $Y$, Kubo $M$ et al. The serum pepsinogen test as a predictor of gastric cancer: the Hisayama study. Am J Epidemiol 2006; 163: $629-637$

136 Dinis-Ribeiro M, da Costa-Pereira A, Lopes C et al. Feasibility and costeffectiveness of using magnification chromoendoscopy and pepsinogen serum levels for the follow-up of patients with atrophic chronic gastritis and intestinal metaplasia. J Gastroenterol Hepatol 2007; 22: $1594-1604$

137 Miki K, Fujishiro M, Kodashima $S$ et al. Long-term results of gastric cancer screening using the serum pepsinogen test method among an asymptomatic middle-aged Japanese population. Dig Endosc 2009; 21: $78-81$

138 Aromaa A, Kosunen TU, Knekt P et al. Circulating anti-Helicobacter pylori immunoglobulin A antibodies and low serum pepsinogen I level 
are associated with increased risk of gastric cancer. Am J Epidemiol 1996; 144: $142-149$

139 Fukuda H, Saito D, Hayashi S et al. Helicobacter pylori infection, serum pepsinogen level and gastric cancer: a case-control study in Japan. Jpn J Cancer Res 1995; 86: 64-71

140 Kikuchi S, Wada O, Miki Ket al. Serum pepsinogen as a new marker for gastric carcinoma among young adults. Research Group on Prevention of Gastric Carcinoma among Young Adults. Cancer 1994; 73: $2695-2702$

141 Knekt P, Teppo L, Aromaa A et al. Helicobacter pylori IgA and IgG antibodies, serum pepsinogen I and the risk of gastric cancer: changes in the risk with extended follow-up period. Int J Cancer 2006; 119: $702-705$

142 Kodoi A, Yoshihara M, Sumii Ket al. Serum pepsinogen in screening for gastric cancer. J Gastroenterol 1995; 30: 452 -460

143 Kokkola A, Louhimo J, Puolakkainen P et al. Helicobacter pylori infection and low serum pepsinogen I level as risk factors for gastric carcinoma. World J Gastroenterol 2005; 11: 1032 - 1036

144 Kwak MS, Kim N, Lee HS et al. Predictive power of serum pepsinogen tests for the development of gastric cancer in comparison to the histologic risk index. Dig Dis Sci 2010; 55: 2275-2282

145 Miki K, Ichinose M, Kawamura $N$ et al. The significance of low serum pepsinogen levels to detect stomach cancer associated with extensive chronic gastritis in Japanese subjects. Jpn J Cancer Res 1989; 80: $111-114$

146 Nomura AM, Stemmermann GN, Samloff IM. Serum pepsinogen I as a predictor of stomach cancer. Ann Intern Med 1980; 93: 537 - 540

147 Parsonnet J, Samloff IM, Nelson LM et al. Helicobacter pylori, pepsinogen, and risk for gastric adenocarcinoma. Cancer Epidemiol Biomarkers Prev 1993; 2: 461 - 466

148 Parthasarathy G, Maroju NK, Kate V et al. Serum pepsinogen I and II levels in various gastric disorders with special reference to their use as a screening test for carcinoma stomach. Trop Gastroenterol 2007; 28: $166-170$

149 Ren JS, Kamangar F, Qiao YL et al. Serum pepsinogens and risk of gastric and oesophageal cancers in the General Population Nutrition Intervention Trial cohort. Gut 2009; 58: 636-642

150 Sasazuki S, Inoue M, Iwasaki M et al. Japan Public Health Center Study Group Effect of Helicobacter pylori infection combined with CagA and pepsinogen status on gastric cancer development among Japanese men and women: a nested case-control study. Cancer Epidemiol Biomarkers Prev 2006; 15: 1341 - 1347

151 Shiotani $A$, Iishi $H$, Uedo $N$ et al. Histologic and serum risk markers for noncardia early gastric cancer. Int J Cancer 2005; 115: 463 - 469

152 So JB, Yeoh KG, Moochala $S$ et al. Serum pepsinogen levels in gastric cancer patients and their relationship with Helicobacter pylori infection: a prospective study. Gastric Cancer 2002; 5: 228-232

153 Sugiu K, Kamada T, Ito $M$ et al. Anti-parietal cell antibody and serum pepsinogen assessment in screening for gastric carcinoma. Dig Liver Dis 2006; 38: $303-307$

154 Yoshihara M, Hiyama T, Yoshida $S$ et al. Reduction in gastric cancer mortality by screening based on serum pepsinogen concentration: a case-control study. Scand J Gastroenterol 2007; 42: 760 - 764

155 Hattori $Y$, Tashiro H, Kawamoto $T$ et al. Sensitivity and specificity of mass screening for gastric cancer using the measurment of serum pepsinogens. Jpn J Cancer Res 1995; 86: 1210 - 1215

156 Kitahara F, Kobayashi K, Sato T et al. Accuracy of screening for gastric cancer using serum pepsinogen concentrations. Gut 1999; 44: 693 697

157 Westerveld $B D$, Pals $G$, Lamers $C B$ et al. Clinical significance of pepsinogen $A$ isozymogens, serum pepsinogen $A$ and $C$ levels, and serum gastrin levels. Cancer 1987; 59: $952-958$

158 You WC, Blot WJ, Zhang $L$ et al. Serum pepsinogens in relation to precancerous gastric lesions in a population at high risk for gastric cancer. Cancer Epidemiol Biomarkers Prev 1993; 2: 113-117

159 Yoshihara M, Sumii K, Haruma $K$ et al. Correlation of ratio of serum pepsinogen I and II with prevalence of gastric cancer and adenoma in Japanese subjects. Am J Gastroenterol 1998; 93: 1090-1096

160 Miki K, Ichinose M, Ishikawa KB et al. Clinical application of serum pepsinogen I and II levels for mass screening to detect gastric cancer. Jpn J Cancer Res 1993; 84: 1086-1090

161 Miki K, Morita M, Sasajima $M$ et al. Usefulness of gastric cancer screening using the serum pepsinogen test method. Am J Gastroenterol 2003; 98: 735-739
162 Pharoah PD, Guilford P, Caldas C International Gastric Cancer Linkage Consortium Incidence of gastric cancer and breast cancer in CDH1 (Ecadherin) mutation carriers from hereditary diffuse gastric cancer families. Gastroenterology 2001; 121: 1348-1353

163 Fitzgerald $R C$, Hardwick $R$, Huntsman $D$ et al. Hereditary diffuse gastric cancer: updated consensus guidelines for clinical management and directions for future research. J Med Genet 2010; 47: 436-444

164 Watson P, Vasen HF, Mecklin JP et al. The risk of extra-colonic, extraendometrial cancer in the Lynch syndrome. Int J Cancer 2008; 123 : 444-449

165 Capelle LG, Van Grieken NC, Lingsma HF et al. Risk and epidemiological time trends of gastric cancer in Lynch syndrome carriers in the Netherlands. Gastroenterology 2010; 138: 487 - 492

166 Giardiello FM, Brensinger JD, Tersmette AC et al. Very high risk of cancer in familial Peutz-Jeghers syndrome. Gastroenterology 2000; 119: $1447-1453$

167 van Lier MG, Westerman AM, Wagner A et al. High cancer risk and increased mortality in patients with Peutz-Jeghers syndrome. Gut 2011; 60: 141 - 147

168 Offerhaus GJ, Giardiello FM, Krush AJ et al. The risk of upper gastrointestinal cancer in familial adenomatous polyposis. Gastroenterology 1992; 102: 1980 - 1982

169 Yaghoobi M, Bijarchi R, Narod SA. Family history and the risk of gastric cancer. Br J Cancer 2009; 102: 237 - 242

170 Bakir T, Can G, Erkul S et al. Stomach cancer history in the siblings of patients with gastric carcinoma. Eur J Cancer Prev 2000; 9: 401 - 408

171 La Vecchia C, Negri E, Franceschi $S$ et al. Family history and the risk of stomach and colorectal cancer. Cancer 1992; 70: 50-55

172 Palli D, Galli M, Caporaso NE et al. Family history and risk of stomach cancer in Italy. Cancer Epidemiol Biomarkers Prev 1994; 3: 15 - 18

173 García-González MA, Lanas A, Quintero E et al. Gastric cancer susceptibility is not linked to pro- and anti-inflammatory cytokine gene polymorphisms in whites: a nationwide multicenter study in Spain. Am J Gastroenterol 2007; 102: 1878 - 1892

174 Dhillon PK, Farrow DC, Vaughan TL et al. Family history of cancer and risk of esophageal and gastric cancers in the United States. Int J Cancer $2001 ; 93: 148-152$

175 Minami $Y$, Tateno $H$. Associations between cigarette smoking and the risk of four leading cancers in Miyagi Prefecture, Japan: a multi-site case-control study. Cancer Sci 2003; 94: 540-547

176 Eto K, Ohyama S, Yamaguchi T et al. Familial clustering in subgroups of gastric cancer stratified by histology, age group and location. Eur J Sur Oncol 2006; 32: $743-748$

177 Hong SH, Kim JW, Kim HG et al. Glutathione S-transferases (GSTM1, GSTT1 and GSTP1) and N-acetyltransferase 2 polymorphisms and the risk of gastric cancer. J Prev Med Public Health 2006; 39: 135 140

178 Foschi R, Lucenteforte E, Bosetti C et al. Family history of cancer and stomach cancer risk. Int J Cancer 2008; 123: 1429-1432

179 Bernini M, Barbi S, Roviello $F$ et al. Family history of gastric cancer: a correlation between epidemiologic findings and clinical data. Gastric Cancer 2006: 9: 9-13

180 Rokkas T, Sechopoulos P, Pistiolas D et al. Helicobacter pylori infection and gastric histology in firstdegree relatives of gastric cancer patients: a meta-analysis. Eur J Gastroenterol Hepatol 2010; 22: $1128-1133$

181 IARC Working Group on the Evaluation of Carcinogenic Risks to Humans. Schistosomes, liver flukes and Helicobacter pylori. IARC Working Group on the Evaluation of Carcinogenic Risks to Humans Lyon, 7-14 June 1994. IARC Monogr Eval Carcinog Risks Hum 1994; 61: $1-241$

182 Figueiredo C, Machado JC, Pharoah P et al. Helicobacter pylori and interleukin 1 genotyping: an opportunity to identify high-risk individuals for gastric carcinoma. J Natl Cancer Inst 2002; 94: 1680-1687

183 Amieva MR, El-Omar EM. Host-bacterial interactions in Helicobacter pylori infection. Gastroenterology 2008; 134: 306-323

184 Machado JC, Figueiredo C, Canedo $P$ et al. A proinflammatory genetic profile increases the risk for chronic atrophic gastritis and gastric carcinoma. Gastroenterology 2003; 125: 364-371

185 Huang JQ Zheng GF, Sumanac Ket al. Meta-analysis of the relationship between cagA seropositivity and gastric cancer. Gastroenterology 2003; 125: 1636 - 1644

186 Basso D, Zambon CF, Letley DP et al. Clinical relevance of Helicobacter pylori cagA and vacA gene polymorphisms. Gastroenterology 2008; 135: $91-99$ 
187 El-Omar EM, Carrington M, Chow WH. Interleukin-1 polymorphisms associated with increased risk of gastric cancer. Nature 2000; 404: $398-402$

188 Yin M, Hu Z, Tan D et al. Molecular epidemiology of genetic susceptibility to gastric cancer: focus on single nucleotide polymorphisms in gastric carcinogenesis. Am J Transl Res 2009; 1: 44-54

189 Persson C, Canedo P, Machado JC et al. Polymorphisms in inflammatory response genes and their association with gastric cancer: $\mathrm{A}$ a HuGE systematic review and meta-analyses. Am J Epidemiol 2011; 173: $259-270$

190 Wang P, Xia HH, Zhang JY et al. Association of interleukin-1 gene polymorphisms with gastric cancer: a meta-analysis. Int J Cancer 2007; 120: $552-562$

191 Camargo MC, Mera R, Correa $P$ et al. Interleukin-1beta and interleukin-1 receptor antagonist gene polymorphisms and gastric cancer: a metaanalysis. Cancer Epidemiol Biomarkers Prev 2006; 15: $1674-$ 1687

192 Xue $H$, Lin B, Ni P et al. Interleukin-1B and interleukin-1 RN polymorphisms and gastric carcinoma risk: a meta-analysis. J Gastroenterol Hepatol 2010; 25: 1604-1617

193 Kamangar F, Cheng C, Abnet CC et al. Interleukin-1B polymorphisms and gastric cancer risk - a meta-analysis. Cancer Epidemiol Biomarkers Prev 2006; 15: 1920-1928

194 Loh M, Koh KX, Yeo BH et al. Meta-analysis of genetic polymorphisms and gastric cancer risk: variability in associations according to race. Eur J Cancer 2009; 45: 2562-2568

195 Schlemper RJ, Riddell RH, Kato Y et al. The Vienna classification of gastrointestinal epithelial neoplasia. Gut 2000; 47: 251-255

196 Rugge M, Leandro G, Farinati $F$ et al. Gastric epithelial dysplasia. How clinicopathologic background relates to management. Cancer 1995; 76: $376-382$

197 Rugge M, Cassaro M, Di Mario F et al. Interdisciplinary Group on Gastric Epithelial Dysplasia (IGGED) The long term outcome of gastric non-invasive neoplasia. Gut 2003; 52: 1111 - 1116

198 de Jonge PJ, van Blankenstein M, Looman CW et al. Risk of malignant progression in patients with Barrett's oesophagus: a Dutch nationwide cohort study. Gut 2010; 59: 1030-1036

199 Stryker SJ, Wolff BG, Culp CE et al. Natural history of untreated colonic polyps. Gastroenterology 1987; 93: 1009-1013

200 Munkholm P. Review article: the incidence and prevalence of colorectal cancer in inflammatory bowel disease. Aliment Pharmacol Ther 2003; 18: $021-5$

201 Weinstein WM, Goldstein N. Gastric dysplasia and its management. Gastroenterology 1994; 107: 1543-1559

202 Ching CK. Can we justify resecting all gastric epithelial dysplastic lesions? Gastroenterology 1995; 108: 1955 - 1956

203 Abraham SC, Montgomery EA, Singh VK et al. Gastric adenomas: intestinal type and gastric type adenomas differ in the risk of adenocarcinoma and presence of background mucosal pathology. Am J Surg Pathol 2000; 26: 1276-1285

204 Hosokawa $\mathrm{O}$, Watanabe $\mathrm{K}$, Hatorri $M$ et al. Detection of gastric cancer by repeat endoscopy within a short time after negative examination. Endoscopy 2001; 33: $301-305$

205 de Dombal FT, Price AB, Thompson $H$ et al. The British Society of Gastroenterology early gastric cancer/dysplasia survey: an interim report. Gut 1990; 31: 115-120

206 Sipponen P, Kekki M, Siurali M. Atrophic chronic gastritis and intestinal metaplasia in gastric cancer: comparison with a representative population sample. Cancer 1983; 52: $1062-1068$

207 Hull MJ, Mino-Kenudson M, Nishioka NS et al. Endoscopic mucosal resection: an improved diagnostic procedure for early gastroesophageal epithelial neoplasms. Am J Surg Pathol 2006; 30: 114-118

$208 \mathrm{Kim}$ YJ, Park JC, Kim JH et al. Histologic diagnosis based on forceps biopsy is not adequate for determining endoscopic treatment of gastric adenomatous lesions. Endoscopy 2010; 42: 620-626

209 Kim ES, Jeon SW, Park SY et al. Where has the tumor gone? The characteristics of cases of negative pathologic diagnosis after endoscopic mucosal resection Endoscopy 2009; 41: 739-745

210 Cassaro M, Rugge M, Gutierrez $O$ et al. Topographic patterns of intestinal metaplasia and gastric cancer. Am J Gastroenterol 2000; 95: $1431-1438$

211 Morson BC. Carcinoma arising from areas of intestinal metaplasia in the gastric mucosa. Br J Cancer 1955; 9: 377-385
212 Vannella L, Lahner E, Osborn J et al. Risk factors for progression to gastric neoplastic lesions in patients with atrophic gastritis. Aliment Pharmacol Ther 2010; 31: 1042 - 1050

213 Lahner E, Bordi C, Cattaruzza MS et al. Long-term follow-up in atrophic body gastritis patients: atrophy and intestinal metaplasia are persistent lesions irrespective of Helicobacter pylori infection. Aliment Pharmacol Ther 2005; 22: 471 - 481

214 Van Zanten SJ, Dixon MF, Lee A. The gastric transitional zones: neglected links between gastroduodenal pathology and helicobacter ecology. Gastroenterology 1999; 116: 1217-1229

215 Kimura A, Takemoto T. An endoscopic recognition of the atrophic border and its significance in chronic gastritis. Endoscopy 1969; 1: $87-$ 97

216 Rokkas T, Filipe MI, Sladen GE. Detection of an increased incidence of early gastric cancer in patients with intestinal metaplasia type III who are closely followed up. Gut 1991; 32: 1110-1113

217 Tosi P, Filipe MI, Luzi P et al. Gastric intestinal metaplasia type III cases are classified as low-grade dysplasia on the basis of morphometry. J Pathol 1993; 169: 73 - 78

218 Ramesar KC, Sanders DS, Hopwood D. Limited value of type III intestinal metaplasia in predicting risk of gastric carcinoma. J Clin Pathol 1987; 40: $1287-1290$

219 Conchillo JM, Houben G, de Bruïne A et al. Is type III intestinal metaplasia an obligatory precancerous lesion in intestinal-type gastric carcinoma? Eur J Cancer Prev 2001; 10: 307-312

220 Nozaki K, Shimizu N, Ikehara Y et al. Effect of early eradication on Helicobacter pylori-related gastric carcinogenesis in Mongolian gerbils. Cancer Sci 2003; 94: 235-239

221 Shimizu N, Ikehara Y, Inada K et al. Eradication diminishes enhancing effects of Helicobacter pylori infection on glandular stomach carcinogenesis in Mongolian gerbils. Cancer Res 2000; 60: 1512-1514

222 Maruta F, Sugiyama A, Ishizone S et al. Eradication of Helicobacter pylori decreases mucosal alterations linked to gastric carcinogenesis in Mongolian gerbils. J Gastroenterol 2005; 40: 104-105

223 Pimanov SI, Makarenko EV, Voropaeva AV et al. Helicobacter pylori eradication improves gastric histology and decreases serum gastrin, pepsinogen I and pepsinogen II levels in patients with duodenal ulcer. J Gastroenterol Hepatol 2008; 23: 1666-1671

224 Rokkas T, Pistiolas D, Sechopoulos P et al. The long-term impact of Helicobacter pylori eradication on gastric histology: a systematic review and meta-analysis. Helicobacter 2007; 12: 0232 - 38

225 de Vries AC, Kuipers EJ. Review article: Helicobacter pylori eradication for the prevention of gastric cancer. Aliment Pharmacol Ther 2007; 26: $0225-35$

226 Wang J, Xu L, Shi R et al. Gastric atrophy and intestinal metaplasia before and after Helicobacter pylori eradication: a meta-analysis. Digestion 2011; 83: 253-260

227 Annibale B, Aprile MR, D'ambra G et al. Cure of Helicobacter pylori infection in atrophic body gastritis patients does not improve mucosal atrophy but reduces hypergastrinemia and its related effects on body ECL-cell hyperplasia. Aliment Pharmacol Ther 2000; 14: 625-634

228 Satoh K, Kimura K, Takimoto T et al. A follow-up study of atrophic gastritis and intestinal metaplasia after eradication of Helicobacter pylori. Helicobacter 1998; 3: 236-240

229 Correa P, Fontham ET, Bravo JC et al. Chemoprevention of gastric dysplasia: randomized trial of antioxidant supplements and anti-Helicobacter pylori therapy. J Natl Cancer Inst 2000; 92: 1881 - 1888

230 Mera R, Fontham ET, Bravo LE et al. Long term follow up of patients treated for Helicobacter pylori infection. Gut 2005; 54: 1536- 1540

231 Wong BC, Lam SK, Wong WM. Helicobacter pylori eradication to prevent gastric cancer in a high-risk region of China: a randomized controlled trial. JAMA 2004; 291: 187-194

232 Fuccio L, Zagari RM, Minardi ME et al. Systematic review: Helicobacter pylori eradication for the prevention of gastric cancer. Aliment Pharmacol Ther 2007; 25: 133-141

233 Fuccio L, Zagari RM, Eusebi LH et al. Meta-analysis: can Helicobacter pylori eradication treatment reduce the risk for gastric cancer? Ann Intern Med 2009; 151: 121 - 128

$234 \mathrm{Kim}$ N, Park RY, Cho SI et al. Helicobacter pylori infection and development of gastric cancer in Korea: long-term follow-up. J Clin Gastroenterol 2008; 42: $448-454$

235 Leung WK, Lin SR, Ching JY et al. Factors predicting progression of gastric intestinal metaplasia: results of a randomised trial on Helicobacter pylori eradication. Gut 2004; 53: $1244-1249$ 
236 You WC, Brown LM, Zhang $L$ et al. Randomized double-blind factorial trial of three treatments to reduce the prevalence of precancerous gastric lesions. J Natl Cancer Inst 2006; 98: 974-983

237 Take S, Mizuno M, Ishiki K et al. The effect of eradicating Helicobacter pylori on the development of gastric cancer in patients with peptic ulcer disease. Am J Gastroenterol 2005; 100: 1037-1042

238 Take S, Mizuno M, Ishiki K et al. The long-term risk of gastric cancer after the successful eradication of Helicobacter pylori. J Gastroenterol 2011; 46: 318 - 324

239 Fukase K, Kato M, Kikuchi S et al. Effect of eradication of Helicobacter pylori on incidence of metachronous gastric carcinoma after endoscopic resection of early gastric cancer: an open-label, randomised controlled trial. Lancet 2008; 372: 392 - 397

240 Uemura N, Mukai T, Okamoto S et al. Effect of Helicobacter pylori eradication on subsequent development of cancer after endoscopic resection of early gastric cancer. Cancer Epidemiol Biomarkers Prev 1997; 6: 639-642

241 Toyokawa T, Suwaki K, Miyake Yet al. Eradication of Helicobacter pylori infection improved gastric mucosal atrophy and prevented progression of intestinal metaplasia, especially in the elderly population: a long-term prospective cohort study. J Gastroenterol Hepatol 2010; 25: $544-547$

242 Yang HB, Sheu BS, Wang ST et al. H. pylori eradication prevents the progression of gastric intestinal metaplasia in reflux esophagitis patients using long-term esomeprazole. Am J Gastroenterol 2009; 104 : $1642-1649$

243 Malfertheiner P, Megraud F, O'Morain C et al. Current concepts in the management of Helicobacter pylori infection: the Maastricht III Consensus Report. Gut 2007; 56: 772 - 781

244 Lam SK, Talley NJ. Report of the 1997 Asia Pacific Consensus Conference on the management of Helicobacter pylori infection. J Gastroenterol Hepatol 1998; 13: 1 -12

245 Malfertheiner P, Mégraud F, O'Morain $C$ et al. European Helicobacter Pylori Study Group (EHPSG) Current concepts in the management of Helicobacter pylori infection - the Maastricht 2-2000 Consensus Report. Aliment Pharmacol Ther 2002; 16: 167-180

246 Fock KM, Katelaris P, Sugano K. Second Asia-Pacific Consensus Guidelines for Helicobacter pylori infection. J Gastroenterol Hepatol 2009; 24: $1587-1600$

247 Shin DW, Yun YH, Choi IJ et al. Cost-effectiveness of eradication of Helicobacter pylori in gastric cancer survivors after endoscopic resection of early gastric cancer. Helicobacter 2009; 14: 536-544

248 Wang WH, Huang JQ Zheng GF et al. Nonsteroidal anti-inflammatory drug use and the risk of gastric cancer: a systematic review and metaanalysis. J Natl Cancer Inst 2003; 95: 1784-1791

249 Tian W, Zhao Y, Liu S et al. Meta-analysis on the relationship between nonsteroidal anti-inflammatory drug use and gastric cancer. Eur J Cancer Prev 2010; 19: 288-298

250 Leung WK, $\mathrm{Ng}$ EK, Chan FK et al. Effects of long-term rofecoxib on gastric intestinal metaplasia: results of a randomized controlled trial. Clin Cancer Res 2006; 12: 4766-4772

251 Zhang LJ, Wang SY, Huo XH et al. Anti-Helicobacter pylori therapy followed by celecoxib on progression of gastric precancerous lesions. World J Gastroenterol 2009; 15: 2731 - 2738

252 Hung KH, Yang HB, Cheng HC et al. Short-term celecoxib to regress long-term persistent gastric intestinal metaplasia after Helicobacter pylori eradication. J Gastroenterol Hepatol 2010; 25: 48 - 53

253 Yanaoka $\mathrm{K}$, Oka M, Yoshimura $\mathrm{N}$ et al. Preventive effects of etodolac, a selective cyclooxygenase- 2 inhibitor, on cancer development in ex- tensive metaplastic gastritis, a Helicobacter pylori-negative precancerous lesion. Int J Cancer 2010; 126: 1467-1473

254 Yang HB, Cheng HC, Sheu BS et al. Chronic celecoxib users more often show regression of gastric intestinal metaplasia after Helicobacter pylori eradication. Aliment Pharmacol Ther 2007; 25: 455-461

$255 W u C Y, W u M S, K u o K N$ et al. Effective reduction of gastric cancer risk with regular use of nonsteroidal anti-inflammatory drugs in Helicobacter pylori-infected patients. J Clin Oncol 2010; 28: 2952-2957

256 Plummer M, Vivas J, Lopez G et al. Chemoprevention of precancerous gastric lesions with antioxidant vitamin supplementation: a randomized trial in a high-risk population. J Natl Cancer Inst 2007; 99: 137 146

257 Mason J, Axon AT, Forman D et al. The cost-effectiveness of population Helicobacter pylori screening and treatment: a Markov model using economic data from a randomized controlled trial. Aliment Pharmacol Ther 2002; 16: 559-568

258 Parsonnet J, Harris RA, Hack HM et al. Modelling cost-effectiveness of Helicobacter pylori screening to prevent gastric cancer: a mandate for clinical trials. Lancet 1996; 348: $150-154$

259 Davies R, Crabbe D, Roderick P et al. A simulation to evaluate screening for Helicobacter pylori infection in the prevention of peptic ulcers and gastric cancers. Health Care Manag Sci 2002; 5: 249-258

260 Roderick P, Davies $R$, Raftery J et al. The costeffectiveness of screening for Helicobacter pylori to reduce mortality and morbidity from gastric cancer and peptic ulcer disease: a discrete-event simulation model. Health Technol Assess 2003; 7: 1-86

261 Roderick P, Davies R, Raftery J et al. Cost-effectiveness of population screening for Helicobacter pylori in preventing gastric cancer and peptic ulcer disease, using simulation. J Med Screen 2003; 10: 148 156

262 Leivo T, Salomaa A, Kosunen TU et al. Cost-benefit analysis of Helicobacter pylori screening. Health Policy 2004; 70: 85-96

263 Dan YY, So JB, Yeoh KG. Endoscopic screening for gastric cancer. Clin Gastroenterol Hepatol 2006; 4: 709-716

264 Yeh JM, Kuntz KM, Ezzati M et al. Exploring the cost-effectiveness of Helicobacter pylori screening to prevent gastric cancer in China in anticipation of clinical trial results. Int J Cancer 2009; 124: 157-166

265 Lee YC, Lin JT, Wu HM et al. Cost-effectiveness analysis between primary and secondary preventive strategies for gastric cancer. Cancer Epidemiol Biomarkers Prev 2007; 16: 875-885

266 Lee HY, Park EC, Jun JK et al. Comparing upper gastrointestinal X-ray and endoscopy for gastric cancer diagnosis in Korea. World J Gastroenterol 2010; 16: $245-250$

267 Xie F, Luo N, Blackhouse G et al. Cost-effectiveness analysis of Helicobacter pylori screening in prevention of gastric cancer in Chinese. Int J Technol Assess Health Care 2008; 24: 87-95

268 Xie F, Luo N, Lee HP. Cost effectiveness analysis of population-based serology screening and 13C-urea breath test for Helicobacter pylori to prevent gastric cancer: a markov model. World J Gastroenterol 2008; 14: 3021 - 3027

269 Fendrick AM, Chernew ME, Hirth RA et al. Clinical and economic effects of population-based Helicobacter pylori screening to prevent gastric cancer. Arch Intern Med 1999; 159: 142-148

270 Yeh JM, Hur C, Kuntz KM et al. Cost-effectiveness of treatment and endoscopic surveillance of precancerous lesions to prevent gastric cancer. Cancer 2010; 116: 2941 - 2953

271 Hassan C, Zullo A, Di Giulio E et al. Cost-effectiveness of endoscopic surveillance for gastric intestinal metaplasia. Helicobacter 2010; 15 : $221-226$ 